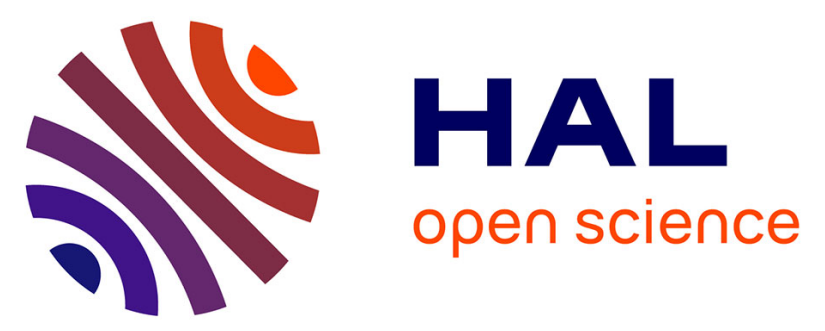

\title{
Longitudinal characterization of cognitive and motor deficits in an excitotoxic lesion model of striatal dysfunction in non-human primates
}

Sonia Lavisse, Susannah Williams, Sophie Lecourtois, Nadja van Camp, Martine Guillermier, Pauline Gipchtein, Caroline Jan, Sébastien Goutal, Leopold Eymin, Julien Valette, et al.

\section{To cite this version:}

Sonia Lavisse, Susannah Williams, Sophie Lecourtois, Nadja van Camp, Martine Guillermier, et al.. Longitudinal characterization of cognitive and motor deficits in an excitotoxic lesion model of striatal dysfunction in non-human primates. Neurobiology of Disease, 2019, 130, pp.104484. 10.1016/j.nbd.2019.104484 . cea-02155538

\section{HAL Id: cea-02155538 https://hal-cea.archives-ouvertes.fr/cea-02155538}

Submitted on 13 Jun 2019

HAL is a multi-disciplinary open access archive for the deposit and dissemination of scientific research documents, whether they are published or not. The documents may come from teaching and research institutions in France or abroad, or from public or private research centers.
L'archive ouverte pluridisciplinaire HAL, est destinée au dépôt et à la diffusion de documents scientifiques de niveau recherche, publiés ou non, émanant des établissements d'enseignement et de recherche français ou étrangers, des laboratoires publics ou privés. 


\title{
Longitudinal characterization of cognitive and motor deficits in an excitotoxic lesion model of striatal dysfunction in non-human primates
}

\author{
Sonia Lavisse ${ }^{\mathrm{a}, \mathrm{b}, 1}$, Susannah Williams ${ }^{\mathrm{a}, \mathrm{b}, 1}$, Sophie Lecourtois ${ }^{\mathrm{a}, \mathrm{b}}$, Nadja van Camp ${ }^{\mathrm{a}, \mathrm{b}}$, \\ Martine Guillermier $^{\mathrm{a}, \mathrm{b}}$, Pauline Gipchtein ${ }^{\mathrm{a}, \mathrm{b}}$, Caroline Jan ${ }^{\mathrm{a}, \mathrm{b}}$, Sébastien Goutal ${ }^{\mathrm{a}, \mathrm{b}}$, \\ Leopold Eymin $^{\mathrm{a}, \mathrm{b}}$, Julien Valette ${ }^{\mathrm{a}, \mathrm{b}}$, Thierry Delzescaux ${ }^{\mathrm{a}, \mathrm{b}}$, Anselme L. Perrier ${ }^{\mathrm{c}, \mathrm{d}}$, \\ Philippe Hantraye ${ }^{\mathrm{a}, \mathrm{b}}$, Romina Aron Badin ${ }^{\mathrm{a}, \mathrm{b}, *}$ \\ ${ }^{a}$ MIRCen, CEA/IBFJ/DRF/LMN, 18 Route du Panorama, 92265 Fontenay-aux-Roses, France \\ ${ }^{\mathrm{b}}$ UMR CEA CNRS 9199-Université Paris Saclay, 18 Route du Panorama, 92265 Fontenay-aux-Roses, France \\ ${ }^{\mathrm{c}}$ Inserm U861, I-STEM, AFM, Corbeil-Essonnes 91100, cedex, France \\ ${ }^{\mathrm{d}}$ UEVE U861, I-STEM, AFM, Corbeil-Essonnes 91100, cedex, France
}

\section{A R T I C L E I N F O}

\section{Keywords:}

Animal model

Non-human primate

Cognitive impairment

Movement disorder

PET imaging

Striatal dysfunction

Huntington's disease

\begin{abstract}
A B S T R A C T
As research progresses in the understanding of the molecular and cellular mechanisms underlying neurodegenerative diseases like Huntington's disease (HD) and expands towards preclinical work for the development of new therapies, highly relevant animal models are increasingly needed to test new hypotheses and to validate new therapeutic approaches. In this light, we characterized an excitotoxic lesion model of striatal dysfunction in non-human primates (NHPs) using cognitive and motor behaviour assessment as well as functional imaging and post-mortem anatomical analyses.

NHPs received intra-striatal stereotaxic injections of quinolinic acid bilaterally in the caudate nucleus and unilaterally in the left sensorimotor putamen. Post-operative MRI scans showed atrophy of the caudate nucleus and a large ventricular enlargement in all 6 NHPs that correlated with post-mortem measurements. Behavioral analysis showed deficits in 2 analogues of the Wisconsin card sorting test (perseverative behavior) and in an executive task, while no deficits were observed in a visual recognition or an episodic memory task at 6 months following surgery. Spontaneous locomotor activity was decreased after lesion and the incidence of apomorphine-induced dyskinesias was significantly increased at 3 and 6 months following lesion. Positron emission tomography scans obtained at end-point showed a major deficit in glucose metabolism and D2 receptor density limited to the lesioned striatum of all NHPs compared to controls. Post-mortem analyses revealed a significant loss of medium-sized spiny neurons in the striatum, a loss of neurons and fibers in the globus pallidus, a unilateral decrease in dopaminergic neurons of the substantia nigra and a loss of neurons in the motor and dorsolateral prefrontal cortex.

Overall, we show that this robust NHP model presents specific behavioral (learning, execution and retention of cognitive tests) and metabolic functional deficits that, to the best of our knowledge, are currently not mimicked in any available large animal model of striatal dysfunction. Moreover, we used non-invasive, translational techniques like behavior and imaging to quantify such deficits and found that they correlate to a significant cell loss in the striatum and its main input and output structures. This model can thus significantly contribute to the pre-clinical longitudinal evaluation of the ability of new therapeutic cell, gene or pharmacotherapy approaches in restoring the functionality of the striatal circuitry.
\end{abstract}

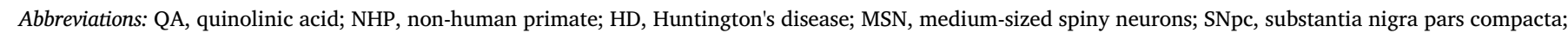

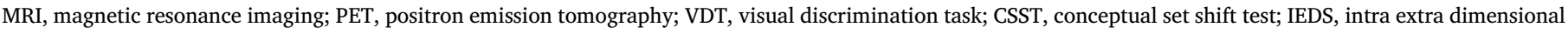
set-shifting; DNMS, delayed no matching to sample; ROI, region of interest; TAC, time activity curves; OD, optical density

* Corresponding author at: Molecular Imaging Research Center (MIRCen), CEA, 18 route du Panorama, Fontenay-aux-Roses 92265, France.

E-mail addresses: sonia.lavisse@cea.fr (S. Lavisse), susannah.williams@sosv.com (S. Williams), sophie.lecourtois@cea.fr (S. Lecourtois), Nadja.van-camp@cea.fr (N. van Camp), martine.guillermier@cea.fr (M. Guillermier), Pauline.gipchtein@cea.fr (P. Gipchtein), caroline.jan@cea.fr (C. Jan), sebastien.goutal@cea.fr (S. Goutal), leopold.eymin@cea.fr (L. Eymin), Julien.valette@cea.fr (J. Valette), Thierry.delzescaux@cea.fr (T. Delzescaux), APERRIER@istem.fr (A.L. Perrier), philippe.hantraye@cea.fr (P. Hantraye), Romina.aron-badin@cea.fr (R. Aron Badin).

${ }^{1}$ Equally contributing authors. 


\section{Introduction}

Huntington's disease (HD) is an autosomal dominant neurodegenerative disease that causes a decline in motor and cognitive function, as well as psychiatric disturbances resulting from the concurrent neuropathological changes in the brain, including loss of medium spiny neurons (MSN) and the presence of proteinaceous aggregates containing Huntingtin (Ross and Tabrizi, 2011). A major challenge in the study of HD pathogenesis and the development of effective therapies is that the currently available animal models cannot fully replicate the stages or the entire spectrum of clinical and pathological features found in HD. HD is a progressive neurodegenerative disease characterized by early cognitive dysfunction that affects executive functions, such as planning and organization skills, verbal fluency, and the cognitive flexibility required to adapt behavior. Severe perseverative behavior, memory loss and even dementia characterize the later stages of the disease. Similarly, subtle motor dysfunction in pre-manifest patients (finger tapping, motor impersistence) is followed by deficits in motor planning and execution that culminate with the appearance of dyskinesias and choreic movements. However, in later stages of the disease, patients are mostly dystonic and akinetic. Other manifestations of the disease have been described like depression and suicidal ideation, oculomotor deficits, dysphagia and emotion recognition (Papoutsi et al., 2014; Walker, 2007). It is therefore not surprising that a disease that progresses over 20 years cannot be captured in a single, short-lived animal model, even those bearing the highest construct and face validity. There is however increasing consensus in the scientific community that all available models are valuable in addressing specific issues, ranging from molecular pathways to therapeutics, and that a combination of models is desirable to increase the predictive value of preclinical efficacy studies (Howland and Munoz-Sanjuan, 2014; Menalled and Brunner, 2014; Morton and Howland, 2013; Pouladi et al., 2013). While there are no naturally occurring animal models of HD, administration of either excitotoxic agents (quinolinate, kainate, ibotenate and malonate) or the mitochondrial toxin 3-nitropropionate (3NP) have been shown to replicate some elements of the disease in both rodents (Beal et al., 1986; Jay and Dunnett, 2007; Shear et al., 1998) and nonhuman primates (NHP) (Brouillet et al., 2005; Burns et al., 1995; Ferrante et al., 1993; Hantraye et al., 1990; Roitberg et al., 2002). The local overexpression of the huntingtin protein using viral vectors is another approach to replicate this monogenic disease (de Almeida et al., 2002; DiFiglia et al., 2007; Franich et al., 2008; Regulier et al., 2003; Senut et al., 2000) or constitutively, using either transgenic (Gray et al., 2008; Hodgson et al., 1999; Mangiarini et al., 1996; Schilling et al., 1999; von Horsten et al., 2003) or knock-in rodent models (Levine et al., 1999; Lin et al., 2001; Menalled and Chesselet, 2002; Shelbourne et al., 1999; Wheeler et al., 1999). Although the histological hallmarks of the disease are reproduced in many independent rodent strains and laboratories, the behavioral symptoms can remain subtle (reviewed in (Crook and Housman, 2011)) and the disease progression can be too severe and rapid (Kosior and Leavitt, 2018), preventing the study of early phases of disease where mostly cognitive and executive impairments are detected in HD patients (Kosior and Leavitt, 2018). Other transgenic rodent, pig and sheep models are more progressive, can present huntingtin aggregates or metabolic abnormalities but show little striatal loss, a major pathological hallmark of the disease in humans that correlates with fronto-striatal dysfunction (Morton, 2018; Reilmann and Schuldenzucker, 2018).

As far as NHP models are concerned, the lentiviral-mediated overexpression of the pathologic (80Q) exon 1 of the human huntingtin protein in the putamen of adult macaques induces motor abnormalities (spontaneous chorea, limb and orofacial dyskinesia, leg dystonia) similar to those observed in HD patients (Palfi et al., 2007). Post-mortem analysis revealed neuronal dysfunction and astrogliosis alongside the presence of neuritic and nuclear ubiquitinated aggregates up to 30 weeks following viral vector injections. In parallel, an outstanding effort was deployed by Chan and colleagues to develop a transgenic macaque model of HD that reproduces the pathological landmarks of the disease, including reduced striatal volume, inflammation (Raper et al., 2016), and shows variable motor deficits, irritability, and subtle fine cognitive alterations in striatal function (Chan et al., 2015; Chan et al., 2014; Korecka et al., 2016; Moran et al., 2015; Yang et al., 2008). This work has advanced important knowledge on the disease itself, however, the small number of animals generated so far and the mild phenotype observed at 5 years of age might not respond to the needs of the HD community for pre-clinical therapeutic efficacy studies.

Our work builds up on results obtained in an excitotoxin-mediated lesion model of HD that has already been shown to induce a clear pattern of cell loss in the striatum, a hallmark of HD, (Beal et al., 1986; Ferrante et al., 1993; Hantraye et al., 1990) accompanied by motor deficits (Burns et al., 1995; Roitberg et al., 2002) and longitudinal anatomical and functional changes (Brownell et al., 1994; Hantraye et al., 1992b; Lavisse et al., 2015; Schumacher et al., 1992) when injected in the putamen. Roitberg et al. reported on motor deficits and used a single simple cognitive test to demonstrate the presence of a fronto-striatal executive deficit three months following QA lesion in all striatal nuclei (Roitberg et al., 2002). However, this study also reported on the detrimental effects on the clinical score of the animals presenting seizures, loss of appetite, aggressiveness and stereotypic behavior. Indeed very few studies report on both the motor and cognitive effect of QA striatal nuclei lesioning in NHPs and no study has documented the long-term effect of QA lesions using a combination of techniques. In this study we describe a NHP model with bilateral lesions in the caudate and a unilateral lesion in the putamen to minimize the impact on general health and allow an extensive behavioral testing using a complex battery, magnetic resonance imaging (MRI) and positron emission tomography (PET) imaging, as well as post-mortem analyses at 6 months post-QA-lesion. Our results reproduce the motor abnormalities previously described when lesioning the putamen unilaterally and show that a specific frontal syndrome can also be induced by injecting QA bilaterally in the caudate nucleus. These functional abnormalities are further supported by anatomical changes in MRI scans and functional changes (metabolism and D2 receptor density) in PET scans. Post-mortem analysis confirms striatal atrophy and a loss of neurons in striatal input and output structures. Overall, the reproducibility, robustness and amplitude of the observed deficits make this model a good candidate for testing neurodegenerative or neurorestorative therapeutic strategies for HD in the pre-clinical setting using translational behavioral and imaging techniques.

\section{Methods}

\subsection{Animals and housing}

All animal studies were conducted according to European regulations (EU Directive 2010/63) and in compliance with Standards for Humane Care and Use of Laboratory Animals of the Office of Laboratory Animal Welfare (OLAW $-\mathrm{n}^{\circ}$ \#A5826-01) in a facility authorized by local authorities (authorization $\mathrm{n}^{\circ} \# \mathrm{~B} 92-032-02$ ). The experimental protocol was reviewed and approved (authorization $\mathrm{n}^{\circ} 12_{-}$074) by the local ethics committee (CETEA $\mathrm{N}^{\circ} 44$ ). All efforts were made to minimize animal suffering and animal care was supervised by veterinarians and animal technicians skilled in the healthcare and housing of NHPs. All primates were housed under standard environmental conditions (12hour light-dark cycle, temperature: $22 \pm 1{ }^{\circ} \mathrm{C}$ and humidity: $50 \%$ ) with ad libitum access to food and water. QA lesion was conducted on a total of six male cynomolgus monkeys (Macaca fascicularis, supplied by Noveprim, Mauritius Island) of a mean age of $4.7 \pm 0.5$ and a mean weight of $5.7 \pm 0.5 \mathrm{~kg}$. Behavioral data from additional intact control monkeys was used for IEDS ( $n=15)$, Memory load $(n=28)$ and DNMS $(n=21)$ cognitive tasks. These monkeys had a mean age of $4.04 \pm 0.61,3.89 \pm 0.94$ and $3.69 \pm 0.50$, and a mean weight of $4.84 \pm 1.42,5.01 \pm 0.90$ and $5.29 \pm 1.22$, respectively. Five to six 
age-matched control animals were also included in the post-mortem analysis.

\section{2. $M R I$}

MRI was performed on all NHPs at baseline in order to allow coregistration with PET images and to determine the stereotactic coordinates for surgery. Anatomical MRI was repeated twice post QA delivery in order to monitor edema and atrophy.

Primates were induced with ketamine $(1 \mathrm{mg} / \mathrm{kg})$ and xylazine $(0.5 \mathrm{mg} / \mathrm{kg})$, maintained anesthetized with an intravenous (i.v.) infusion of propofol $(1 \mathrm{ml} / \mathrm{kg} / \mathrm{h})$ and placed in the magnet in a sphinx position with the head fixed in a stereotactic MRI-compatible frame (M2E, France). NHPs were heated by a hot air flux and their temperature and respiration parameters monitored remotely.

All acquisitions were performed on a horizontal $7 \mathrm{~T}$ Agilent scanner (Palo Alto, CA, USA) equipped with a gradient coil reaching $100 \mathrm{mT} / \mathrm{m}$ ( $300 \mu$ s rise time). A surface coil (RAPID Biomedical GmbH, Rimpar, Germany) was used for transmission and reception. T2-weighted images were acquired using a high-resolution 2D fast spin-echo sequence $\left(469 \times 469 \mu \mathrm{m}^{2}\right.$ in-plane resolution, $1 \mathrm{~mm}$ slice thickness, 70 slices), with echo time TE/Repetition time TR $=20 / 8000 \mathrm{~ms}, 5$ echoes, effective $\mathrm{TE}=52.5 \mathrm{~ms}$ and acquisition time Tacq $=43 \mathrm{~min}$. For $\mathrm{T} 2 \%$ weighted images the parameters used were: $469 \times 469 \mu \mathrm{m}^{2}$ in-plane resolution, $1 \mathrm{~mm}$ slice thickness, 40 slices, $5 \mathrm{TE}$ (from 5.5 to $30 \mathrm{~ms}$ ), repetition time $\mathrm{TR}=2 \mathrm{~ms}$ and acquisition time Tacq $=8 \mathrm{~min}$.

\subsection{Surgery}

Primates were induced with ketamine $(1 \mathrm{mg} / \mathrm{kg})$ and xylazine $(0.5 \mathrm{mg} / \mathrm{kg})$, and maintained anesthetized with an i.v. infusion of propofol $(1 \mathrm{mg} / \mathrm{kg} / \mathrm{h})$ with constant monitoring of blood pressure, heart rate, exhaled $\mathrm{CO} 2$, temperature and respiratory frequencies. NHPs were placed in a stereotactic MRI-compatible frame in a sphinx position with the head resting on a mouth bar and fixed by ear bars.

An intradermal injection of local analgesics (Bupivicaine $(1 \mathrm{mg} / \mathrm{kg}$ ), xylazine with adrenaline $(2 \mathrm{mg} / \mathrm{kg})$ ) was administered before incision of the skin and before suturing the cutaneous plane. A wide spectrum antibiotic was delivered before and after surgery (TLA terramycin long action, $20 \mathrm{mg} / \mathrm{kg}$ ).

All NHPs received bilateral caudate nucleus (AC $+4, A C 0)$ and unilateral left putamen (AC0, AC-2) injections of $80 \mathrm{mMol}$ quinolinic acid (QA) prepared as previously described (Brouillet et al., 1999). Stereotaxic injection coordinates were determined on baseline T2weighted images for each monkey. At each coordinate, a single deposit of $10 \mu \mathrm{l}$ of $80 \mathrm{mM}$ quinolinic acid toxin was injected at a rate of $1 \mu \mathrm{l} /$ min using a Hamilton syringe and 26G needle controlled by a KDS injection micropump (Phymep, France).

\subsection{Behavioral tests}

\subsubsection{Assessment of locomotor activity}

Forty-minute films were acquired in a dedicated room equipped with a custom-made plexiglass cage eight times at baseline ("PRE-QA") to habituate NHPs to the test cage and characterize any stereotypic behavior. At 3 and 6 months following QA-lesion, NHPs were filmed for $40 \mathrm{~min}$ before and $90 \mathrm{~min}$ after being injected with apomorphine $(0.5 \mathrm{mg} / \mathrm{kg}$ Apokinon $5 \mathrm{mg} / \mathrm{ml}$, France, i.m.). After apomorphine injection, only the first $40 \mathrm{~min}$ of the recorded video were considered for quantification, in order to compare similar observation lengths with the pre-apomorphine condition. Ethovision ${ }^{\circledR}$ software (Noldus, Netherlands) was used to quantify the locomotor activity as mean distance moved in $\mathrm{cm}$ (Vadori et al., 2015). The presence of abnormal movements (dyskinesias) in the face and body trunk (upper and lower limbs) was manually scored every $5 \mathrm{~min}$ throughout the $40 \mathrm{~min}$-film by an experienced observer (Palfi et al., 1996).

\subsubsection{Assessment of cognitive function}

NHPs were trained to perform tests on touch screens (Elotouch, France) equipped with an automatic dispenser to deliver fruit pellet rewards (Fruit Crunchies TM, Bio-Serv, USA) and using software developed in-house. No dietary or hydric restrictions were applied. The different tests were either carried out in a working station or in an individual test cage. The testing battery was designed to measure cognitive flexibility, memory and executive function.

The visual discrimination task (VDT) (Basile and Hampton, 2011) was used to determine if the primates could distinguish between three different shapes with different colors presented side-by-side in the middle of the screen. Each working session consisted of 20 trials in which the animal had to identify the rewarded object by trial and error. The cut-off time was $60 \mathrm{~s}$. NHPs were trained until they reached the criterion (100\% success score) at baseline and the success score on a single working session was recorded at 3 and 6 months following QAlesion.

The Conceptual Set Shift Test (CSST), an adaptation for monkeys of the Wisconsin card sorting test, was delivered as previously described (Moore et al., 2005). Briefly, three images of different color and shape were presented randomly on the tactile screen and one object was rewarded. Once the rewarded object was reproducibly selected (success criterion: 10 consecutive correct responses), the rule was changed and the reward was "shifted" to another object with a different shape (dimension 1) or color (dimension 2). Three consecutive shifts between the two dimensions were thus applied, using the same success criterion to go from one shift to the next. The CSST was carried out at baseline, and 3 and 6 months following QA lesion using a different series of objects at each timepoint. The total number of successes, the perseverative errors, the omitted trials, the mean time of response and the broken sets (8) were recorded for each step.

The Intra extra dimensional set-shifting (IEDS) test was administered to all NHPs for the first time at 6 months following QA-lesion in working sessions consisting of 50 trials as previously described (Barnett et al., 2010; Dias et al., 1996; Roberts et al., 1988) and the cut-off time was $60 \mathrm{~s}$. Briefly, the animal is required to shift attention across 2 dimensions of a complex set of stimuli composed of shapes and lines. Choosing the correct target and dimension (shape or line) on 10 consecutive trials was required to progress to the next shift. The total number of trials to complete the 5 steps of the test was measured and compared to results obtained in a group of 15 healthy intact controls tested in the same conditions. The mean number of trials \pm 2 SD obtained in the healthy intact NHPs was applied as a cut-off threshold if QA-lesioned primates did not reach success criterion in one or more steps of the test. Total number of trials to complete the steps, omitted trials and errors were recorded for each step.

The delayed no matching to sample (DNMS) test was delivered only at 6 months following QA lesion to evaluate visual recognition memory. The test was administered as previously described (Weed et al., 1999) using a short delay ( $2 \mathrm{~s}$ ) between the presentation and choice phases and a cut-off time of $60 \mathrm{~s}$. Each session consisted of 40 trials, and the total number of sessions required to reach the $90 \%$ success criterion, and the number of omitted trials and errors were recorded. Results were compared to those obtained in a group of healthy intact controls performing the test under the same conditions $(n=21)$. A cut-off threshold was applied when 1400 trials (35 sessions) were reached.

Memory load is a measure of long term memory that was programmed in house specifically to test hippocampal function. A total of 60 photographic images including animals, inanimate objects or flowers were presented in pairs, randomized to the left or right of the screen, and the animal learnt which one was rewarded by trial and error. Pairs of images were randomly assigned to each trial across working sessions to avoid associative memory. Each working session consisted of 30 trials with a cut-off time of $60 \mathrm{~s}$, and the total number of trials to reach the $90 \%$ success criterion, omitted trials and errors were recorded. Results were compared to those obtained in a group of 
healthy intact controls that were tested under the same conditions $(n=28)$. A cut-off threshold was applied after 27 working sessions if QA-lesioned primates did not reach success.

For all behavioral tests performed before (PRE-QA) and after QA injection (i.e. locomotor activity, VDT and the CSST), control values are the PRE-QA values. For all behavioral test learnt after QA lesions (i.e. IEDS, Memory load and DNMS), control values were extracted from a database of intact animals of $n=15$ for IEDS, $\mathrm{n}=28$ for Memory load and $n=21$ for DNMS respectively.

\subsection{PET imaging}

\subsubsection{PET acquisition}

${ }^{18} \mathrm{~F}$-Fluorodeoxyglucose $\left({ }^{18} \mathrm{~F}\right.$-FDG, IBA Molecular, Gif-sur-Yvette, France) and ${ }^{18} \mathrm{~F}$-Fallypride (Sahin et al., 2014) PET scans were performed in all NHPs at 6 months following QA lesion to assess glucose metabolism and D2/D3 receptor occupancy, respectively. Results were compared to those obtained in healthy intact NHPs $\left(n=26\right.$ for ${ }^{18}$ F-FDG and $n=14$ for ${ }^{18} \mathrm{~F}$-Fallypride) scanned following the same PET protocol.

Primates were induced with ketamine $(1 \mathrm{mg} / \mathrm{kg})$ and xylazine $(0.5 \mathrm{mg} / \mathrm{kg})$ and maintained anesthetized with an i.v. infusion of propofol $(1 \mathrm{ml} / \mathrm{kg} / \mathrm{h})$. They were placed in a PET dedicated stereotacticlike animal holder with the head fixed by ear bars. Body temperature was maintained using a heating blanket (Homeothermic Blanket Control Unit; Harvard Apparatus, MA, USA) and blood pressure, heart rate, exhaled $\mathrm{CO}_{2}$, and respiratory frequencies were monitored remotely. PET imaging was performed using a Concorde Focus220 microPET scanner (Siemens, TN, USA). A 17-min-transmission scan was first performed for attenuation correction, followed by a $60 \mathrm{~min}\left({ }^{18} \mathrm{~F}\right.$ FDG) or $120 \mathrm{~min}\left({ }^{18} \mathrm{~F}\right.$-Fallypride) dynamic emission scan acquired in 2D mode. Radiotracers were injected i.v. at a dose of $155.3 \pm 5.1$ or $167.2 \pm 6.2 \mathrm{MBq}$ for ${ }^{18} \mathrm{~F}$-FDG or ${ }^{18} \mathrm{~F}$-Fallypride respectively. Images were reconstructed as previously described (Lavisse et al., 2015). Arterial blood samples were drawn from the femoral artery throughout both PET examinations to establish the time-course of total radioactivity in the arterial plasma, to assess the glycemia and to analyze ${ }^{18} \mathrm{~F}$ Fallypride metabolites. Plasma ${ }^{18} \mathrm{~F}$-Fallypride metabolites were separated from the parent compound by radio-chromatography as previously published (Peyronneau et al., 2013) and radioactivity was counted with a gamma counter (Cobra, PerkinElmer, Waltham, MA, USA) that was cross-calibrated with the PET scanner. The radioactivity due to unchanged ${ }^{18} \mathrm{~F}$-Fallypride was expressed as a fraction of the total radiolabeled peak area. All blood data were corrected for radioactive decay from the injection time and the plasma time-activity curve (TAC) was corrected by the fraction of unchanged radioligand.

\subsubsection{PET image analysis}

Collected time frames were summed to create an integrated image for manual co-registration with the T2-weighted MRI using an in-house anatomo-functional image processing software (Anatomist; http:// www.brainvisa.info) and a dedicated PMOD software (PMOD Technologies). Anatomical regions of interest (ROI) were automatically delineated on the putamen and caudate nuclei, the IHC regions (see \$2.6.2) and cortical/subcortical regions on individual MRI images using the CIVM atlas and the Primatologist segmentation pipeline for the macaque brain (Balbastre et al., 2017). After T2-MRI and PET-co-registration, the mean activity of each ROI was extracted from the dynamic PET data as a TAC. Kinetic analysis was performed using a specialized PMOD toolbox (PMOD Technologies, Zurich, Switzerland) after loading TAC and arterial metabolite-corrected input function. Quantification of the D2/D3 receptor densities $\left({ }^{18} \mathrm{~F}\right.$-Fallypride) was based on the graphical Logan plot analysis developed for reversible receptor systems and the Binding Potential $\left(\mathrm{BP}_{\mathrm{ND}}\right)$, an index of neuroreceptor-binding-site density, was the primary outcome measure. For the ${ }^{18}$ F-FDG analysis, we used the Patlak graphical plot method to quantitatively assess the cerebral metabolic rate of glucose (CMRGlu, lumped constant $=0.34$ )

To obtain maximal use of image information without a priori knowledge, parametric images of $\mathrm{BP}_{\mathrm{ND}}$ and CMRGlu were generated and analysed on a voxel-by-voxel basis using Statistical Parametric Mapping (SPM5, Wellcome Trust Centre for Neuroimaging, London, United Kingdom). The procedure of spatial normalization and its validation have been previously described (Ashburner, 2012). Images were spatially normalized in the SPM space into a macaque ${ }^{18} \mathrm{~F}$-FDG or ${ }^{18} \mathrm{~F}$ Fallypride specific template and were smoothed with an isotropic Gaussian kernel of $3 \mathrm{~mm}$. Spatially-normalized images were masked to remove extracerebral signals that would disrupt the global normalization.

\subsection{Post-mortem analysis}

\subsubsection{Immunohistochemistry (IHC)}

Ten to 12 months post-injection, NHPs were induced with ketamine $(1 \mathrm{mg} / \mathrm{kg})$ and xylazine $(0.5 \mathrm{mg} / \mathrm{kg}$ ) before receiving an i.v. lethal dose of pentobarbital $(100 \mathrm{mg} / \mathrm{kg}$, Sanofi, France). NHPs were then transcardially perfused with $0.9 \% \mathrm{NaCl}$ followed by $4 \%$ paraformaldehyde and the brains were extracted and cryoprotected in incrementing PBSsucrose gradients before histological processing. Post-fixed brains were sectioned coronally with a freezing stage microtome (Leica SM2400) into $40 \mu \mathrm{m}$ thick sections. Free floating tissue sections were incubated for $48 \mathrm{~h}$ at $4{ }^{\circ} \mathrm{C}$ with the following primary antibodies: DARPP-32 1:2000 (AP08628PU-N, Acris Herford, Germany), NeuN 1:5000 (MAB377, Millipore, Billerica, MA), Tyrosine Hydroxylase (TH) 1:500 (22,941, Immunostar, Hudson, Wisconsin) diluted in PBS, $0.2 \%$ triton, and $3 \%$ normal goat serum solution. After washing, sections were incubated for $1 \mathrm{~h}$ at room temperature with the appropriate biotinylated secondary antibodies (anti-rabbit, anti-mouse, 1:1000 Vector laboratories) and the avidin-biotinylated enzyme complex (Vectorstain $\mathrm{ABC}$ kit) applied and visualized using diaminobenzidine. Post-mortem histological analysis on the 6 QA-lesioned primates and on 5-6 age-matched controls included qualitative morphological analysis at different magnifications, region segmentations and stereological cell counts performed using a computer-assisted analysis system consisting of a Leica DM6000 microscope and Mercator software (ExploraNova, La Rochelle, France).

\subsubsection{Volume measurements}

Striatal volume estimates were performed on $1.28 \mathrm{~mm}$ spaced sections stained for DARPP-32. Twelve to 16 serial sections covering the rostro-caudal extent of the structure were required for the caudate nucleus and the putamen, while 6 to 7 sections were required for the globus pallidus. The outlines of the anatomical structures were delineated on serial sections using Mercator software and the areas were calculated. The volume of the structures was estimated using the Cavalieri method (Gundersen et al., 1999).

\subsubsection{Stereological counts}

Unbiased stereological counts were performed using the optical fractionator procedure (West et al., 1991). The total number of neurons was counted in the motor cortex (Inase et al., 1996; Takada et al., 1998; Tokuno et al., 1999) projecting to the putamen, in the dorsolateral prefrontal (DLP) cortex (Selemon and Goldman-Rakic, 1985; Yeterian and Pandya, 1991), in the cortical area 24 (Ferry et al., 2000) projecting to the caudate nucleus, in the substantia nigra (SN) projecting to the dorsal striatum (Joel and Weiner, 2000; Lynd-Balta and Haber, 1994), and in the external globus pallidus (GPe) that receives projections from both caudate nucleus and putamen (Hazrati and Parent, 
1992; Hedreen and DeLong, 1991). For all the studied regions, only error coefficients below 0.10 were accepted. Because higher error coefficients were found in the internal globus pallidus (GPi), this region was excluded from this analysis.

In the motor cortex, 6 serial sections spaced of $1.28 \mathrm{~mm}$ were stained for NeuN and counts were performed bilaterally over the whole cortical thickness. The region corresponding to the primary motor cortex (Brodmann area 4) localized anterior to the central sulcus was delimited medially by the cingulate sulcus and laterally by the central sulcus, as shown in Supplementary Fig. S1A.

In the DLP cortex, a region anterior to the arcuate sulcus and dorsal to the principal sulcus corresponding to the Brodmann area $46 \mathrm{~d}$ was considered (see Suppl. Fig. 1B). Counts were performed bilaterally on the dorsal bank of the principal sulcus (area 46d) on 6 serial NeuNstained sections, spaced of $320 \mu \mathrm{m}$.

In the cortical area 24,6 serial sections spaced of $320 \mu \mathrm{m}$ were stained for NeuN and bilateral counts were performed dorsally to the corpus callosum in the anterior parts of both area 24a and area $24 \mathrm{~b}$ (Suppl. Fig. 1C). In the GPe, 12-13 serial sections spaced of $640 \mu \mathrm{m}$ were stained for NeuN and counts were performed bilaterally (Suppl. Fig. 2A). In the SNpc, 9-11 serial sections spaced of $640 \mu \mathrm{m}$ were stained for TH and counts were performed bilaterally in the ventral part of the SN that project mostly to the sensorimotor putamen. The delimitation of the ventral SN was defined ventrally by a line crossing the middle of the horizontal band and laterally by a vertical line crossing the middle of the red nucleus (Suppl. Fig. 2B).

\subsubsection{Optical density (OD) measurements}

OD measurements were performed in the QA-lesioned primates on 3 striatal coronal sections stained for TH spaced of $2.56 \mathrm{~mm}$ and centred on the anterior commissure level. TH-stained sections were first scanned using Axioscan Z1 scanner (Zeiss) to guarantee constant lighting level. Then the left and right putamen and caudate were delineated on the sections and the optical density was measured using Mercator ${ }^{\circledast}$ software (Explora Nova). The striatal OD values were normalized to the OD measurements in the cingulate cortex in each animal as an internal control to account for any differences in the staining of the sections.

\subsection{Statistical analyses}

All data are presented as mean \pm sem unless otherwise indicated. Statistical analysis was performed using the $\mathrm{R}$ project free software version 3.3.1. Differences between groups were assessed using a twoway ANOVA followed by Tukey post hoc testing for all IHC measurements ( $n=5-6$ control animals). "Treatment" (PRE- and POST-QA injection) and IHC anatomical regions were defined as explanatory variables. For behavioral tests, a Wilcoxon rank sum test was used for the IEDS (controls $n=15$ ), Memory Load (controls $n=28$ ) and DNMS

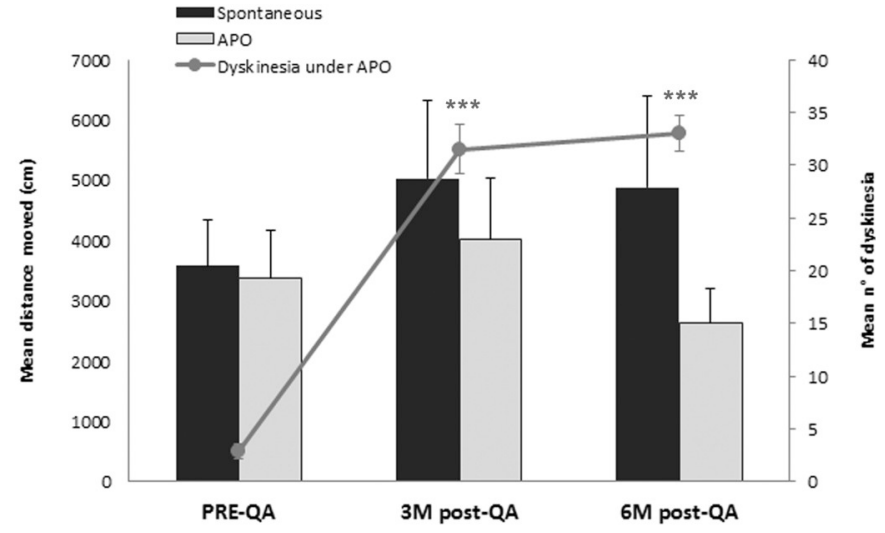

Fig. 2. Longitudinal assessment of spontaneous and apomorphine-induced locomotor activity.

The mean distance moved (cm) (bars) and the mean number of dyskinesias (curve) were determined in 30-minute films in the absence of apomorphine (black) and in 40-minute films after i.m. administration of $0.5 \mathrm{mg} / \mathrm{kg}$ of apomorphine (grey) at baseline (PRE-QA) and 3 and 6 months post-lesion (postQA). Values are reported as mean \pm s.e.m. ${ }^{* * *} p<0.001$ for dyskinesia at $3 \mathrm{M}$ / $6 \mathrm{M}$ compared to baseline.

(controls $n=21$ ) tasks, a one-way ANOVA followed by the Tukey post hoc was used for the VDT and the CSST tasks, and finally a two-way ANOVA was used for the motor assessments, looking at distance moved and dyskinesia numbers with "APO" (with and without) and "Time" (PRE-QA, 3 M/6 M POST-QA)- as explanatory variables. Using analysis of variances, residuals were normally distributed and variances were homogeneous. Correlations were performed using Spearman's rank correlation coefficient. For PET imaging, a Wilcoxon rank sum test was performed for the ROI-based approach ( $n=26$ controls for ${ }^{18}$ F-FDG and $n=14$ for the ${ }^{18}$ F-Fallypride scans). For group comparisons at a voxel level in SPM5, t-statistical parametric maps of positive (PET outcomes higher in the QA-lesioned group than in the control group) and negative contrasts were calculated using a threshold of $p<0.003$ (uncorrected). Effect size was reported using partial eta-squared $\eta_{P}{ }^{2}$ (Navarro, 2015) for analyses of variance or $r$ when using Wilcoxon rank sum test or the Tukey's Post Hoc Test. The partial eta-squared values were calculated with the lsr and heplots packages (Fox et al., 2018). The effect size $r$ values were calculated like previously described (Field et al., 1991) for the Tukey's Post Hoc Test and using the compute.es package for the Wilcoxon rank sum tests (http://cran.r-project.org/ web/packages/compute.es). In these packages, the absolute magnitude of difference between groups was determined using Cohen d effect sizes $(0.2=$ small; $0.5=$ moderate; $0.8=$ large effect $)$. The level of significance for all hypotheses was set at $p<0.05$.
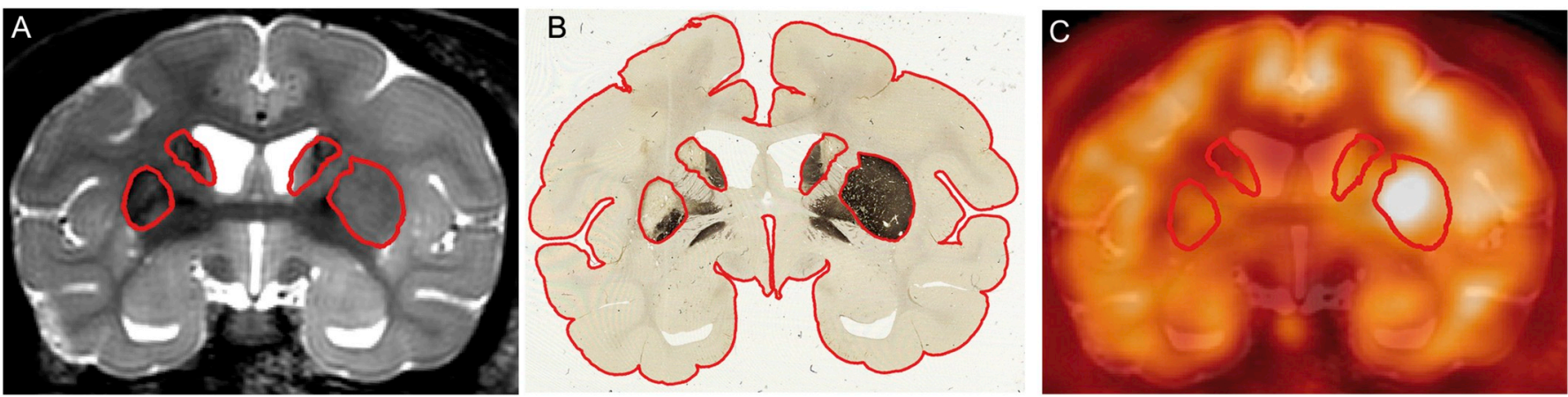

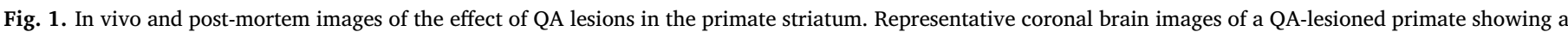

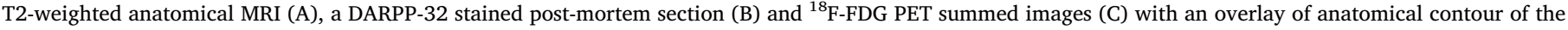
caudate and putamen (red lines). (For interpretation of the references to color in this figure legend, the reader is referred to the web version of this article.) 


\section{Results}

\subsection{Surgical targeting and anatomical imaging}

Anatomical MRI scans acquired at 3 and 6 months following QAlesion were compared to baseline scans. The location of all surgical targets was confirmed in all NHPs in both the caudate nuclei and putamen. No anatomical abnormalities or adverse effects following surgery were observed. Post-lesion scans revealed areas of hypointense signal corresponding to iron-containing hemosiderin deposits as expected from this model (Anderson, 2011; Hantraye et al., 1990; Kruer et al., 2012) (Fig. 1A). This loss of signal was accentuated by tissue atrophy bilaterally in the caudate and unilaterally in the putamen. Conversely, an increase in the hyperintense signal of the ventricles was observed in all NHPs as a consequence of cell loss in the caudate nuclei. A significant positive correlation (Spearman $r=0.81, p=0.005$ ) was found between the striatal volume delimited on end-point MRI images and on DARPP-32 stained post-mortem sections (Fig. 1A, B). Furthermore, there is a clear match between the anatomical regions showing reduced DARPP-32 staining following QA lesion (i.e. left and right caudate and left putamen) and the affected regions on the MRI and PET images compared to the unlesioned putamen (right) (Fig. 1A, B, C).

\subsection{Characterization of the functional impact of the $Q A$ lesion in vivo}

\subsubsection{Assessment of motor behaviour}

Spontaneous locomotor activity was not different from baseline in QA-lesioned primates at 3 months $(p=0.70, r=0.42)$ and 6 months ( $p=0.75, r=0.51$ ) after lesion (Fig. 2, black bars). Before QA lesion (PRE-QA), apomorphine injection did not induce any changes in the mean distance moved and, accordingly, the ratio (with/without APO) was of $1.17 \pm 0.12$ across the 6 monkeys. The mean distance moved under apomorphine at both 3 and 6 months post-QA lesion showed a tendency to decrease but was not significantly different from pre-apomorphine values at the same timepoints $(p=0.89, r=0.20$ and $p=0.89, r=0.17$, respectively) (Fig. 2). The total number of dyskinesias on the other hand was significantly increased at 3 and 6 months after QA-lesion compared to baseline $(+682.3 \%$ and $+688.2 \%$, $\left.p<0.001 ; \eta_{P}^{2}=0.85\right)$ but was not significantly different between 3 and 6 months ( $p=0.99, r=-0.02$ ) post-QA (Fig. 2, curve). Qualitatively, the animals spent the same amount of time displaying orofacial dyskinesias (42\%) and dyskinesias of the trunk (upper and lower limbs) $(57 \%)$ at both timepoints following lesion.

\subsubsection{Assessment of cognitive behaviour}

VDT was administered at baseline and at 3 and 6 months after QA lesion to control for performance, attentional or off-target deficits that could bias interpretation of results on other tests in the cognitive battery. No significant differences in success score were observed between baseline (100\%), 3 (91 $\pm 3 \% ; p=0.44, r=0.56)$ and 6 months (93 $\pm 3 \% ; p=0.65, r=0.53)$ after lesion.

The CSST was administered repeatedly over time to assess the functional integrity of the fronto-striatal pathway. The total number of trials required to complete all steps of the test was not significantly different between baseline (total $=3265)$ and the $3($ total $=4224)$ and 6 months $\quad($ total $=4050) \quad$ post-lesion timepoints $\quad(p=0.82$; $\left.\eta_{P}{ }^{2}=0.026\right)$. However, at 6 months, QA-lesioned primates required significantly more trials to go from Shift1 to Shift2 than either at baseline $(p=0.001, r=-0.74)$ or at 3 months post-injection ( $p<0.001, r=0.34$ ) (light grey bars, Fig. 3). The number of perseverative errors, omitted trials, broken sets and mean respond time was not significantly different across steps $\left(p=0.83747 / \eta_{P}{ }^{2}=0.061\right.$; $p=0.8947 / \eta_{P}{ }^{2}=0.004 ; \quad p=0.5831 / \eta_{P}{ }^{2}=0.023 ; \quad p=0.9012 /$ $\eta_{P}{ }^{2}=0.023$, respectively $)$ and timepoints $\left(p=0.38808 / \eta_{P}{ }^{2}=0.001\right.$; $p=0.8480 / \eta_{P}{ }^{2}=0.007 ; \quad p=0.3516 / \eta_{P}{ }^{2}=0.045 ; \quad p=0.3516 /$ $\eta_{P}{ }^{2}=0.045$, respectively) (Suppl. Table 1 ).

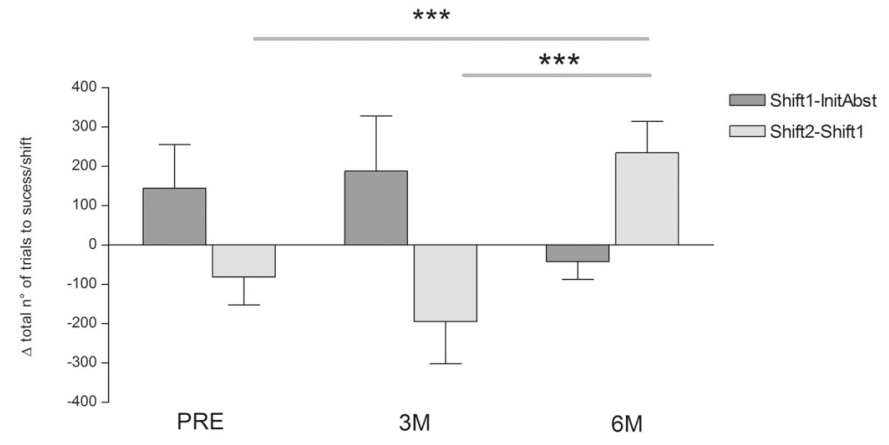

Fig. 3. Longitudinal follow-up of cognitive performance on the conceptual set shifting task in QA-lesioned NHPs at baseline (PRE), 3 and 6 months after lesion.

The difference $(\Delta)$ between the total number of trials needed to successfully complete one shift and perform the next shift is represented per shift and per timepoint. No significant difference is observed in the number of trials required to go from Initial Abstraction to Shift 1 at baseline, 3 or 6 months post-lesion (dark grey bars). A significant increase in the number of trials needed to go from Shift 1 to Shift 2 is observed at 6 months post-lesion compared to baseline and compared to the 3 months timepoint (light grey bars). Values are represented as mean \pm s.e.m. ${ }^{* * *} p \leq 0.001$

At 6 months post-QA lesion, NHPs were tested on "de novo" learning of three tests: IEDS, Memory30 and DNMS and results were compared to a group of healthy intact NHPs.

The number of total trials to success in the IEDS test was significantly higher in the QA-lesioned primates compared to controls $(p<0.001, r=-0.42)$. This significant difference in performance held true for all steps of the test $(p=0.0008, r=-0.73 / \mathrm{SD}$, $p=0.039, r=-0.45 / \mathrm{CD}, p=0.005, r=-0.60 /$ IDS and $p=0.004$, $r=-0.62 / \mathrm{EDS})$ except for the first reversal step $(p=0.22, r=-0.27)$ (Fig. 4). The number of errors was significantly increased in INTRAand-EXTRA DS in QA-lesioned primates compared to controls ( $p=0.0043, r=-0.64 ; p=0.005, r=-0.61$ ).

The DNMS test was delivered using a short 2 second delay to weigh the level of performance of executive function. QA-lesioned primates required significantly more trials to complete the test compared to healthy intact controls including successes, errors and omitted trials $(p=0.001, p=0.0087, p=0.017, r=-0.61$ ).

There was no significant difference in the success trials, omitted responses and errors needed to learn the memory load test when comparing QA-lesioned primates and healthy intact controls $(p=0.31$, $r=-0.17 ; p=0.051, r=-0.54, p=0.074, r=-0.49$ ).

The raw data from all cognitive tests are provided in Supplementary Table S1.

\subsubsection{Assessment of glucose metabolism and $D 2 / 3$ receptor occupancy by PET imaging}

${ }^{18}$ F-FDG scans showed a significant decrease in CMRGlu of $-44.5 \%$ in the right and left caudate $(p<0.001, r=-0.91)$ and of $-41.6 \%$ in the left putamen ( $p<0.001, r=-0.91$, respectively) (see Table 1 and Figs. 1C, 5A). ${ }^{18} \mathrm{~F}$-FDG CMRGlu values in all extra-striatal regions are detailed in Supplementary Table S2. Of all extra-striatal regions, CMRGlu values were the lowest in the left pallidum (GPe + GPi) $(-30 \%, p<0.001, r=-0.83)$ in lesioned compared to healthy primates. In IHC regions co-registered on ${ }^{18}$ F-FDG PET images, metabolism was significantly decreased by $-23 \%$ in the left and right DLP cortex $(p=0.02, r=-0.53$ and $p=0.032, r=-0.51)$, by $\sim-24 \%$ in the motor cortex $(p=0.024, \mathrm{r}=-0.53)$ and by $\sim-17 \%$ in the cortical Area $24(p=0.02, \mathrm{r}=-0.53$ and $p=0.04, r=-0.48$ in left and right hemisphere).

Quantification of ${ }^{18} \mathrm{~F}$-Fallypride scans showed that $\mathrm{BP}_{\mathrm{ND}}$ was decreased in all lesioned regions, by $-61 \%$ in both right and left caudate ( $p<0.001, r=-0.85$ and $p<0.001, r=-0.82$, respectively) and 
Table 1

Quantification of PET scans 6 months following QA lesion in healthy intact controls and QA-lesioned primates.

\begin{tabular}{|c|c|c|c|c|c|}
\hline PET Ligand & Region & Hemisphere & Controls & QA-lesioned & $\% \Delta$ (QA - Controls) \\
\hline \multirow[t]{4}{*}{${ }^{18}$ F-FDG (CMRGlu) } & Caudate & Left & $23.3 \pm 3.4$ & $12.9 \pm 1.2$ & $-44.5_{* * *}$ \\
\hline & & Right & $22.7 \pm 2.3$ & $12.6 \pm 1.0$ & $-44.6_{* * *}$ \\
\hline & Putamen & Left & $23.8 \pm 2.1$ & $13.93 \pm 1.2$ & $-41.6_{* * *}$ \\
\hline & & Right & $24.7 \pm 2.9$ & $19.5 \pm 1.9$ & -21.1 \\
\hline \multirow[t]{4}{*}{${ }^{18} \mathrm{~F}$-Fallypride $\left(\mathrm{BP}_{\mathrm{ND}}\right)$} & Caudate & Left & $44.4 \pm 4.4$ & $18.8 \pm 3.3$ & $-57.5_{* * *}$ \\
\hline & & Right & $44.6 \pm 4.3$ & $17.0 \pm 2.6$ & $-61.9_{* * *}$ \\
\hline & Putamen & Left & $51.7 \pm 4.3$ & $20.9 \pm 3.1$ & $-59.6_{* * *}$ \\
\hline & & Right & $50.7 \pm 4.7$ & $39.2 \pm 4.1$ & $-22.7 *$ \\
\hline
\end{tabular}

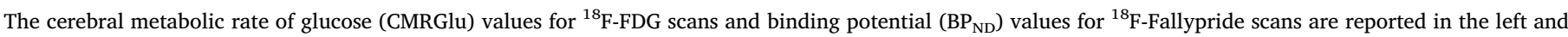

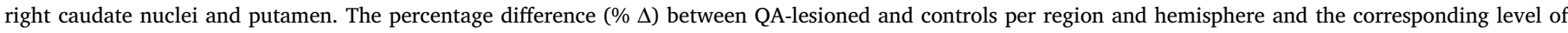
significance is reported in the last column. Values are presented as mean \pm s.e.m.

${ }^{*} p<0.05$.

*** $p<0.001$.

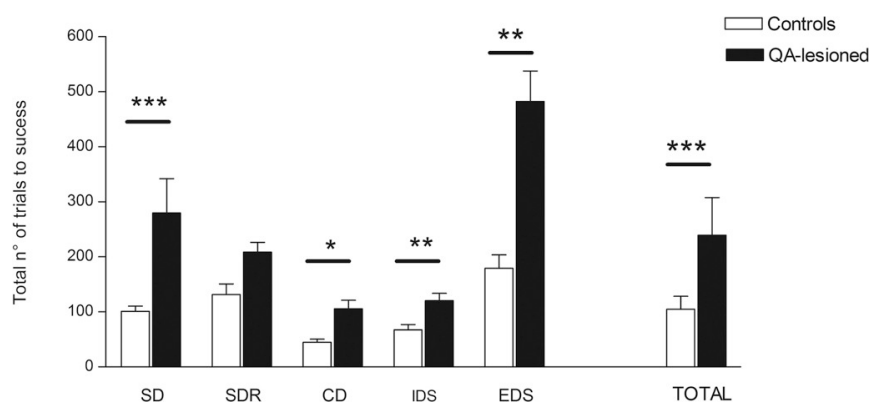

Fig. 4. Cognitive performance on end-point de novo learning of the Intra-extra dimensional set-shifting (IEDS) task in QA-lesioned NHPs (black bars) and healthy intact controls (white bars).

The mean total number of trials required to complete each of the five successive steps of the test (Simple discrimination, SD; Simple discrimination reversal, SDR; Compound discrimination, CD; Intradimensional shift, IDS; Extradimensional shift, EDS) and to complete all five steps (TOTAL) of the test are significantly higher in QA-lesioned primates. Values are represented as mean \pm s.e.m.. ${ }^{*} p<0.05 ; * * p<0.01 ; * * * p<0.001$.

by $-60 \%$ in the left putamen ( $p<0.001, r=-0.82$ ) (see Table 1 , Fig. 5A). Interestingly, a decrease of $-23 \%$ was observed in the right unlesioned putamen ( $p=0.03, r=-0.45)$.

Moreover, SPM was used to perform $t$-tests of CMRGlu and $\mathrm{BP}_{\mathrm{ND}}$ parametric images between the QA-lesioned and control groups at 6 months. The CMRGlu analysis revealed that the QA lesion induced a significant decrease (threshold of $p<0.003$ ) in glucose metabolism limited to the lesioned area of the striatum (bilateral caudate and left putamen) as shown by the CMRGlu parametric map in Fig. 5B. The $\mathrm{BP}_{\mathrm{ND}}$ analysis showed similar results for $\mathrm{D} 2$ receptor density with in addition a significant decrease in the pallidum ipsilateral to the lesioned putamen. These results are consistent with those obtained through the ROI-based approach for the same threshold (Suppl. Table 2).

\subsection{Post-mortem characterization of the lesion by immunohistochemistry}

Table 2 summarizes the volume estimates and stereological cell counts performed in the striatum, $\mathrm{SNpc}$, and cortical regions of lesioned primates and healthy intact controls.

The striatal volume as calculated on DARPP-32 stained serial sections showed an overall significant loss of medium-sized spiny neurons (MSNs) and consequent atrophy in QA-lesioned primates compared to controls $\left(p<0.001 ; \eta_{P}{ }^{2}=0.78\right)$. Moreover, significant differences in DARPP-32 volumes were found independently in the left and right caudate ( $p<0.001 ; r=0.91$ and $p<0.001 ; r=0.90$, respectively) and left putamen ( $p<0.001, r=0.92)$ of QA-lesioned NHPs compared to controls. The volume of the right unlesioned putamen was not significantly different from that of controls $(p=0.43, r=0.49)$. The overall estimates of the GPe volume were significantly reduced $\left(p<0.001 ; \eta_{P}{ }^{2}=0.57\right)$ following QA lesion, and were more significantly reduced in the left $(-47.5 \%, p<0.001, r=0.84)$ than in the right hemisphere $(-29.0 \%, p=0.005, r=0.70)$ compared to controls. Moreover, stereological counts in the GPe of QA-lesioned primates showed a significant loss of NeuN + cell bodies compared to controls $(-26 \%$ in both right and left hemispheres, $p=0.02$; $\left.\eta_{P}{ }^{2}=0.24\right)$. No significant differences in NeuN volume were found in the GPi (left: $p=0.2, r=0.67$; right: $p=0.96, r=0.49$ ) but due to a high error coefficient, the analysis of stereological counts was not pursued in this region.

The levels of TH staining in the striatum of lesioned primates were determined by optical density bilaterally in the caudate and putamen, and in the cingulate cortex as an internal control. The TH staining was decreased by $-61 \%$ bilaterally in the caudates $(p<0.001$, $r=-0.97)$ and by $-57.4 \%$ in the left putamen $(p<0.001$, $r=-0.95$ ). Interestingly, a significant decrease was also detected in the unlesioned right putamen $(-53.1 \%, p<0.001, r=-0.90)$. Stereological counts in the SNpc revealed a significant $-21 \%$ loss of TH + neurons in the ipsilateral (left) hemisphere of QA-lesioned primates compared to controls ( $p=0.04, r=0.67$ ) while no significant decrease in $\mathrm{TH}+$ cells was observed in the contralateral hemisphere $(p=0.99$, $r=-0.03$ ).

A significant $16 \%$ reduction in the number of $\mathrm{NeuN}+$ cells was observed in the motor cortex of lesioned NHPs compared to intact controls $\left(p=0.04 ; \eta_{P}^{2}=0.19\right)$ and no significant difference between right and left hemispheres $(p=0.39, r=0.17)$. Similarly, stereological counts revealed a significant atrophy in the DLP cortex $(-13 \%$, $\left.p=0.01 ; \eta_{P}{ }^{2}=0.27\right)$ whereas no change in NeuN + counts was observed in Area 24 in QA-lesioned primates compared to healthy intact controls $\left(p=0.68 ; \eta_{P}{ }^{2}=0.008\right)$.

\section{Discussion}

Huntington's disease is a monogenic disease that presents a complex phenotype including cognitive, motor and psychiatric symptoms. It is challenging to recapitulate all aspects of the disease in a single animal model while respecting a reasonable timeframe for its generation. The need to test therapeutic approaches however drives the development and refinement of models in different species to address different questions. While the field has mainly focused on the use of small animal models and in particular transgenic mouse models, large animal models and, in particular NHP, represent an important stepping stone towards the clinic. Large animal models have been the most challenging to generate in terms of time and cost, and several models are under study today including transgenic sheep (Jacobsen et al., 2010), minipigs (Baxa et al., 2013; Yan et al., 2018), and macaques (Chan et al., 2015; Yang et al., 2008) but none has proved successful in modelling HD 

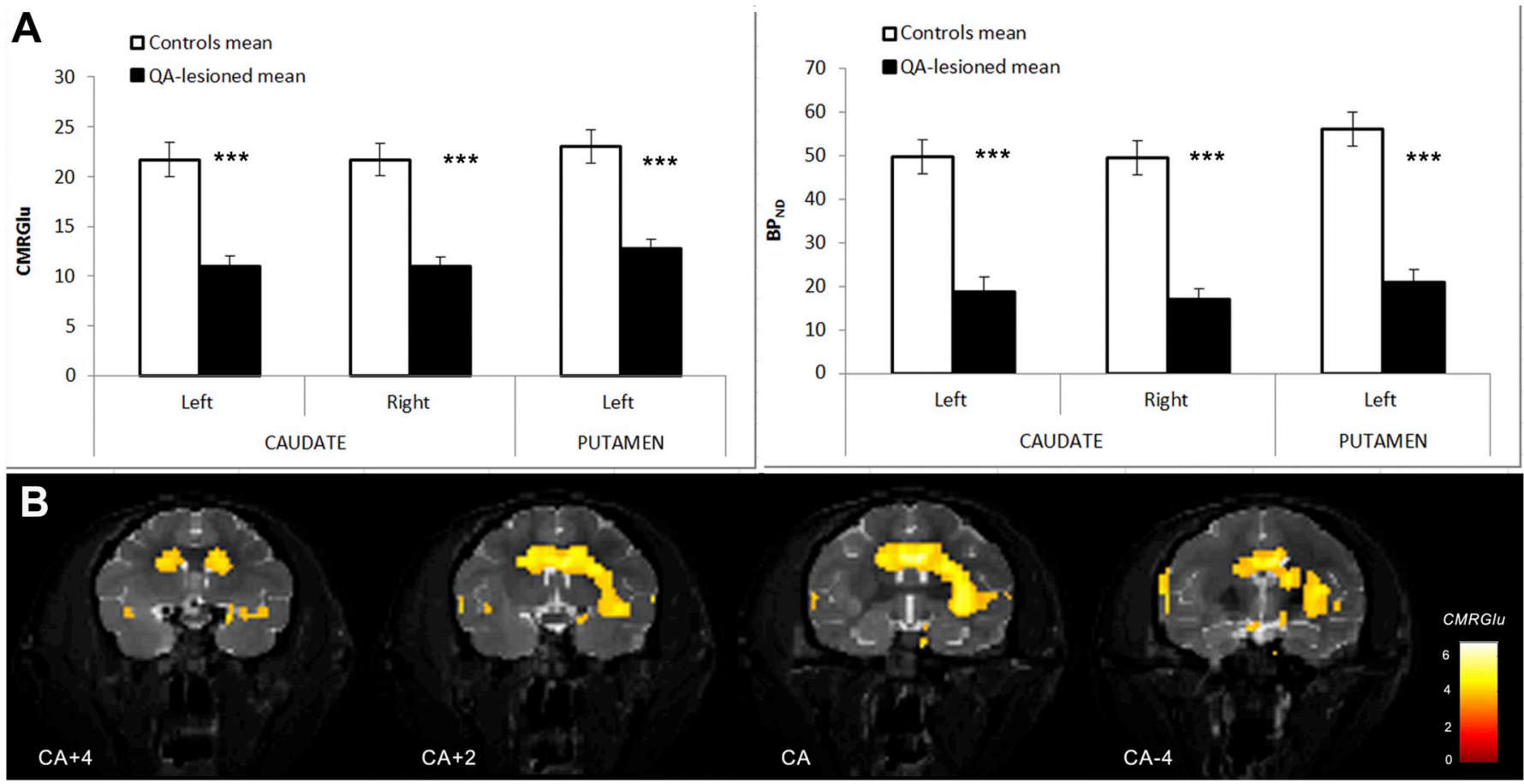

Fig. 5. PET imaging quantification of ${ }^{18} \mathrm{~F}$-FDG and ${ }^{18} \mathrm{~F}$-Fallypride scans acquired in healthy intact controls and in QA-lesioned NHPs at end-point.

A- CMRGlu and $\mathrm{BP}_{\mathrm{ND}}$ values in the regions injected with $\mathrm{QA}$ in lesioned (black bars) animals, i.e. left and right caudate and left putamen, compared to the same regions in intact controls (white bars) $(* * * p<0.001)$. B- Statistical parametric maps (radiological convention) showing the negative CMRGlu differences in lesioned compared to healthy intact NHP exceeding a threshold of $p=0.003$ (uncorrected), according to the color scale that codes T-values. The parametric maps for this comparison are overlaid on representative coronal MRI slices at different anteroposterior levels from anterior commissure AC +4 to AC-4 mm.

Table 2

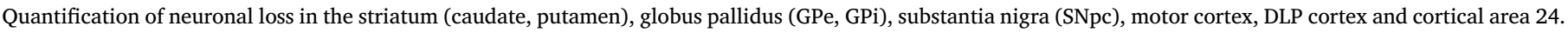

\begin{tabular}{|c|c|c|c|c|c|c|c|c|}
\hline Quantification & Region & Controls & QA-lesioned & $\begin{array}{l}\% \Delta(\mathrm{QA}- \\
\text { Controls })\end{array}$ & Hemisphere & Controls & QA-lesioned & $\begin{array}{l}\% \Delta \text { (QA - } \\
\text { Controls) }\end{array}$ \\
\hline \multirow{4}{*}{$\begin{array}{l}\text { Volume }\left(\mathrm{mm}^{3}\right) \\
\qquad(\text { DARPP32+) }\end{array}$} & \multirow[t]{2}{*}{ Caudate } & \multirow[t]{2}{*}{$416.4 \pm 14.0$} & \multirow[t]{2}{*}{$237.3 \pm 10.4$} & \multirow[t]{2}{*}{$-43.0_{* * *}$} & Left & $411.6 \pm 19.1$ & $240.8 \pm 14.3$ & $-41.5 * *$ \\
\hline & & & & & Right & $421.2 \pm 22.5$ & $233.8 \pm 16.3$ & $-44.5_{* *}$ \\
\hline & \multirow[t]{2}{*}{ Putamen } & \multirow{2}{*}{$550.8 \pm 17.1$} & \multirow{2}{*}{$409.1 \pm 27.5$} & \multirow{2}{*}{$-25.7_{* * *}$} & Left & $551.6 \pm 25.2$ & $327.3 \pm 16.2$ & $-40.7 * *$ \\
\hline & & & & & Right & $550 \pm 26.2$ & $490.8 \pm 19.6$ & -10.7 \\
\hline \multirow[t]{4}{*}{ Volume $\left(\mathrm{mm}^{3}\right)(\mathrm{NeuN}+)$} & \multirow[t]{2}{*}{$\mathrm{GPe}$} & \multirow[t]{2}{*}{$100.2 \pm 3.2$} & \multirow[t]{2}{*}{$61.7 \pm 5.5$} & \multirow{2}{*}{$-38.4_{* * *}$} & Left & $101.3 \pm 4.5$ & $53.2 \pm 7.7$ & $-47.5 * * *$ \\
\hline & & & & & Right & $99 \pm 4.9$ & $70.3 \pm 6.8$ & $-29.0 * *$ \\
\hline & \multirow[t]{2}{*}{ GPi } & \multirow[t]{2}{*}{$46.9 \pm 2.2$} & \multirow[t]{2}{*}{$34.1 \pm 2.8$} & \multirow[t]{2}{*}{-27.3} & Left & $48 \pm 3.1$ & $30.0 \pm 4.8$ & -37.5 \\
\hline & & & & & Right & $45.8 \pm 3.4$ & $38.2 \pm 1.9$ & -16.6 \\
\hline \multirow[t]{4}{*}{$\mathrm{OD}(\mathrm{TH}+)$} & \multirow[t]{2}{*}{ Caudate } & \multirow[t]{2}{*}{$19.0 \pm 0.9$} & \multirow[t]{2}{*}{$7.4 \pm 0.74$} & \multirow[t]{2}{*}{$-61.0_{\text {米* }}$} & Left & $18.7 \pm 1.0$ & $7.1 \pm 0.7$ & $-62.0_{* * *}$ \\
\hline & & & & & Right & $19.3 \pm 0.9$ & $7.7 \pm 0.8$ & $-60.1_{* * *}$ \\
\hline & \multirow[t]{2}{*}{ Putamen } & \multirow[t]{2}{*}{$15.5 \pm 0.7$} & \multirow[t]{2}{*}{$6.9 \pm 0.6$} & \multirow[t]{2}{*}{$-55.2_{\text {米水 }}$} & Left & $15.3 \pm 0.7$ & $6.5 \pm 0.6$ & $-57.4_{* * *}$ \\
\hline & & & & & Right & $15.8 \pm 0.8$ & $7.4 \pm 0.7$ & $-53.1_{* * *}$ \\
\hline \multirow{2}{*}{$\begin{array}{c}\text { Stereology }\left(* 10^{4}\right) \\
(\mathrm{NeuN}+)\end{array}$} & \multirow[t]{2}{*}{$\mathrm{GPe}$} & \multirow[t]{2}{*}{$220,681.1 \pm 16,470.7$} & \multirow[t]{2}{*}{$162,221.5 \pm 14,921.1$} & \multirow[t]{2}{*}{$-26.5_{*}$} & Left & $22.7 \pm 2.7$ & $16.3 \pm 2.8$ & -28.0 \\
\hline & & & & & Right & $21.5 \pm 2.1$ & $16.1 \pm 1.4$ & -24.9 \\
\hline \multirow[t]{2}{*}{ Stereology $\left(* 10^{4}\right)(\mathrm{TH}+)$} & $\mathrm{SNpc}$ & $75,348.3 \pm 3302.8$ & $68,407.4 \pm 2584.2$ & -9.2 & Left & $8 \pm 0.5$ & $6.3 \pm 0.3$ & $-21.6 *$ \\
\hline & & & & & Right & $7 \pm 0.4$ & $7.1 \pm 0.4$ & -0.8 \\
\hline Stereology $\left(* 10^{4}\right)$ & Motor cortex & $538.8 \pm 27.1$ & $451.5 \pm 27.8$ & $-16.2_{*}$ & Left & $524.3 \pm 34.6$ & $431 \pm 34.3$ & -17.8 \\
\hline$(\mathrm{NeuN}+)$ & & & & & Right & $553.3 \pm 44.2$ & $472 \pm 45.4$ & -14.7 \\
\hline Stereology $\left(* 10^{4}\right)$ & DLP cortex & $137.8 \pm 46.7$ & $119.6 \pm 46.5$ & $-13.3_{*}$ & Left & $140.7 \pm 6.4$ & $124.4 \pm 62.3$ & -11.6 \\
\hline$(\mathrm{NeuN}+)$ & & & & & Right & $135 \pm 7.2$ & $114.7 \pm 6.9$ & -15.0 \\
\hline Stereology $\left(* 10^{4}\right)$ & Cortical Area & $108.6 \pm 68.0$ & $104.6 \pm 62.1$ & -3.6 & Left & $111.9 \pm 11.5$ & $99.2 \pm 9.1$ & 11.4 \\
\hline$(\mathrm{NeuN}+)$ & 24 & & & & Right & $105.2 \pm 8.1$ & $110 \pm 8.6$ & 4.6 \\
\hline
\end{tabular}

The reduction in volume or total cell number for each region and hemisphere is reported as mean \pm s.e.m. for intact and QA-lesioned primates. The percentage difference $(\% \Delta)$ between QA-lesioned and control NHPs and the corresponding level of significance per region are reported in the fifth column. The percentage difference $(\% \Delta)$ between QA-lesioned and control NHPs and the corresponding level of significance per hemisphere are reported for each region in the last column. Primary antibodies used for each brain region are specified on the first column. Volumes are reported in $\mathrm{mm}^{3}$ while stereological counts are reported as total numbers of cells $\times 10^{4}$.

$$
\begin{aligned}
& { }^{*} p<0.05 . \\
& { }^{* *} p<0.01 . \\
& { }^{* * *} p<0.001 .
\end{aligned}
$$


(Pouladi et al., 2013). Unlike rodents, the human and NHP striatum is divided into a caudate nucleus and a putamen and the proportions of different cell types (e.g. Calretinin, Parvalbumin and NADPH positive neurons) within these regions that enables a more complex striatal microcircuitry is much more similar between the human and NHP than the rat (reviewed in (Cicchetti et al., 2000)). Moreover, functional techniques like PET imaging or electroencephalography, used to explore deficits and therapeutic efficacy, have a resolution that is not compatible with a small brain size. Finally, the mouse brain contains approximately 70 million neurons compared to 6 billion in macaques and 86 billion in humans (Herculano-Houzel, 2009). This should be considered when scaling-up treatments looking at biodistribution of drugs and gene therapy products or at the number of cells required to achieve neural circuit reconstruction in a cell therapy strategy (Emerich et al., 2006; Isacson et al., 1990; Isacson et al., 1989; Schumacher et al., 1992). These anatomical characteristics of the NHP brain can support the pertinence of the species and its use as a model for pre-clinical efficacy studies.

Intraparenchymal or systemic administration of excitotoxins has been used to generate reproducible and less costly models in rodents and non-human primates (reviewed in (Aron Badin and Hantraye, 2012)). Previous studies have lesioned various combinations of striatal nuclei with QA in the NHP: either solely the putamen (Burns et al., 1995), both the putamen and caudate nucleus unilaterally (Brownell et al., 1994; Emerich et al., 2006; Ferrante et al., 1993; Schumacher et al., 1992) or bilaterally (Emerich et al., 1997). Such studies have mostly used immunohistochemistry to document changes in neurons and interneurons, by looking at the reduction in markers like DARPP32, Calbindin, substance $\mathrm{P}$, and $\mathrm{TH}$, and the sparing of other cell types like ChAT and NADPH positive cells (Brownell et al., 1994; Emerich et al., 1997; Emerich et al., 2006; Ferrante et al., 1993; Roitberg et al., 2002; Schumacher et al., 1992). Only a few studies have also combined the post-mortem assessment with an in vivo characterization of the motor impairment (Brownell et al., 1994; Burns et al., 1995; Roitberg et al., 2002; Schumacher et al., 1992), and brain imaging (Hantraye et al., 1992a,b; Lavisse et al., 2015).

The severity of the bilateral lesions in the striatum has been documented in rodents (Nash et al., 1991; Pettibone et al., 1978; Tulipan et al., 1986) as leading to a lethal phenotype. Only one study in primate has performed bilateral lesions in the caudate and putamen, resulting in larger detrimental impacts on the day to day well-being of the animal (Roitberg et al., 2002). In view of the complex assessments and the duration of our working hypothesis, it was ethically unacceptable to perform full lesions of both caudate and putamen bilaterally. The chosen lesion paradigm builds on the existing literature on the ability of unilateral putaminal lesions to generate motor deficits (Hantraye et al., 1990) and provides novel proof of concept of the effect of bilateral caudate lesions on cognition.

Indeed, the strength of the work presented here is the in depth characterization of changes in cognitive performance and capacity to retain previously learnt rules, and the ability of lesioned NHPs to learn new rules after bilateral QA administration to the caudate nuclei. These two capabilities were assessed through behavioral tests delivered on touch screens at baseline, and at two timepoints post-lesion, and also by delivering certain tests exclusively post-lesion. Our results show that there are significant fronto-striatal deficits both in the retention and the execution of rules acquired before lesioning (CSST) and rules learnt after lesioning (IEDS, DNMS), reminiscent of HD. In particular, the increase in the number of success and error trials in the IEDS task in QAlesioned primates, shows an inability to maintain an attentional set and transfer this knowledge from one shape to another (i.e. intra-dimensional shift IDS), and to shift an attentional set from one dimension (shape) to another (line) (i.e. extra-dimensional shift EDS) (Dias et al., 1996). Moreover, primates showed no deficit in performing the VDT test repeatedly over time allowing us to exclude a potential global effect of the lesion. The lack of deficit in the episodic memory test delivered only at end-point also supports the specificity of the lesion to the frontostriatal circuitry which is known to be affected in HD. While the deficits in retention we observe have already been described using the object retrieval-detour task test (Roitberg et al., 2002) to our knowledge, this is the first time that cognitive deficits in learning, execution and retention in specific tests and not in control tests are described to this extent in this lesion model.

The unilateral lesion of the putamen did not give rise to significant changes in spontaneous locomotor activity over time. However, the acute systemic administration of apomorphine revealed the presence of dyskinesias that were significantly increased at 3 and 6 months postlesion compared to baseline but did not aggravate between the 3 and 6 month timepoints. In particular, limb and orofacial dyskinesias were observed. Because the locomotor activity profile under apomorphine is influenced by the type of dyskinesia, the presence of repetitive orofacial abnormal movements (licking and biting behaviours that "block" the animal in a position) can explain the lack of increase in distance moved.

These behavioral deficits were associated with functional striatal alterations quantified in PET scans. In particular, when compared to healthy intact controls, QA-lesioned NHPs showed a very significant decrease in glucose metabolism bilaterally in caudate and unilaterally in the lesioned putamen. Similarly, ${ }^{18}$ F-Fallypride scans performed at 6 months post-QA showed that the binding was severely decreased bilaterally in caudates and putamen of lesioned primates compared to controls. The fact that the unlesioned right putamen also showed a reduction in ${ }^{18}$ F-Fallypride scans could be explained by a compensatory reduction in post-synaptic D2/3 receptor density. In fact, adaptive changes in the plasticity of the nigro-striatal circuitry and a reactive compensation of the hemisphere contralateral to the lesion have been reported as a means to avoid an imbalance between the left and right nigro-striatal pathways (Leviel et al., 1979). This is further supported by the lack of overt locomotor phenotype (Meyer et al., 1993) and the bilateral putaminal reduction in TH staining measured by OD in our model.

We further characterized the impact of the QA lesion in the injected nuclei and in the main input and output structures of the striatum using MRI and IHC. While HD ultimately leads to a global cell loss in the brain, the primary degeneration is the loss of MSNs that accounts for $90-95 \%$ of the striatal neuron population in the caudate and putamen (Yelnik et al., 1991). Directly targeting MSNs with QA in our model caused a significant loss of DARPP-32 immunostaining bilaterally in the caudate nucleus and unilaterally in the putamen. Interestingly, this cell loss leading to atrophy could be observed and estimated in vivo using MRI. In fact, an increase in the size of hyperintense signal coming from the enlarged ventricles and the increase in the hypointensity of the signal coming from the lesioned brain areas due to the accumulation of iron allowed to estimate the volume of the remaining striatum on anatomical T2-weighted scans. The resulting high and significant correlation between MRI striatal volume and post-mortem DARPP-32-positive striatal volume further validates MRI as an in vivo follow-up tool to estimate grey matter loss.

As known from HD patients, other nuclei in the basal ganglia can also be affected as a function of the severity of the striatal atrophy (Vonsattel, 2008; Vonsattel and DiFiglia, 1998). Consistent with these clinical observations, a loss of TH-positive dopaminergic neurons in the ventral portion of the left SNpc that projects to the left lesioned putamen was observed in our model. This can result from either a direct neurotoxic action of QA on NMDA receptors on the dopaminergic terminals in the striatum, or a down-regulation of the nigrostriatal pathway in response to the loss of the MSNs described in patients (Schwab et al., 2015). The first hypothesis (direct action) seems less likely since excitotoxins have been shown to leave structurally intact dopamine afferent fibers within infused areas (Bonanno et al., 1989; Isacson et al., 1985). Moreover, pure dopaminergic unilateral lesions of SN (Nieoullon et al., 1977) or MFB (Hefti et al., 1980) in 6-OHDA rodents do not affect the contralateral dopaminergic function (TH labelling or dopamine concentration). This suggests that the second 
hypothesis of a compensatory downregulation is the most likely explanation. Indeed, some groups have found a significant decrease in the number and size of DA neurons in the midbrain of post-mortem tissue of HD patients as well as differences in the expression of TH within the nigrostriatal pathway (Bedard et al., 2011; Ferrante and Kowall, 1987). Moreover, the fact that we observe a bilateral reduction in TH levels in the striatum and no spontaneous rotation behavior in QA-lesioned primates, further supports this view. A significant decrease in GPe volume, that receives projections principally from the caudate and the anterior putamen, was also observed bilaterally in lesioned NHPs compared to intact healthy controls. Stereological counts in this region confirmed overall cell loss in the right and left hemispheres but to a lesser extent. The fact that the impact of the QA striatal lesion on GPe volume was greater than the impact on actual cell loss in this region suggests that a severe deafferentation (decrease in fibers) rather than an actual cell degeneration occurs in the striatal output structure, making this NHP model particularly pertinent for the assessment of cell therapy products or neurotrophic factors that can reconstruct and reconnect the striatal circuitry.

Interestingly, recent publications have highlighted the fact that although cortical atrophy is an essential feature of HD neuropathology, there is a great variability in cortical thinning, volume, cell loss, and cell morphology changes (reviewed in (Waldvogel et al., 2012)). In particular, motor and behavioral changes could be attributed to cell loss in the motor and anterior cingulate areas of the cortex differentially (Thu et al., 2010). Our results show an overall significant decrease in NeuN-positive cells bilaterally in the motor cortex projecting to the putamen and DLP cortex projecting to the caudate nucleus but not in area 24 of QA-lesioned NHPs compared to intact healthy controls.

The two major limitations of this model compared to the human disease are the acute nature of the lesion and the absence of huntingtin protein aggregates. Although the mechanism of degeneration in HD is different than in the excitotoxic lesion model, we show that targeting the caudate and putamen not only has direct effects on these nuclei but also results in the disruption of cortico-striatal and striato-nigral pathways that underlie the functional deficits observed on cognitive, motor and PET imaging assessments and produce many of the deficits reported in HD patients (Papoutsi et al., 2014). Moreover, while the time required to generate such a robust NHP model is inferior to that of existing large transgenic animal models, it is possible to follow up animals for several years after treatment to evaluate the long-term safety and efficacy of new therapeutic approaches. Although it is impossible to assess treatments directed against the pathological accumulation of huntingtin protein, we believe that this model can significantly contribute to the scaling-up of neuroprotective and cell replacement strategies as well as the use of new delivery devices before their clinical application.

Supplementary data to this article can be found online at https:// doi.org/10.1016/j.nbd.2019.104484.

\section{Acknowlegments}

This work was supported by grants from the French National Agency for Research TK-SAFE Program No. ANR-07-RIB-016, HD-SCT program ANR-2010-RFCS-003, NeurATRIS: A Translational Research Infrastructure for Biotherapies in Translational Neurosciences (Investissement d'Avenir - ANR-11-INBS-0011, A.L.P), the laboratoire d'Excellence Revive (Investissement d'Avenir; ANR-10-LABX-73, A.L.P), and the European Community's 7th Framework Program (Repair-HD FP7-HEALTH-602245).

\section{References}

Anderson, L.J., 2011. Assessment of iron overload with T2* magnetic resonance imaging. Prog. Cardiovasc. Dis. 54, 287-294.

Aron Badin, R., Hantraye, P., 2012. Designing primate models to assess the prodromal phase of Huntington's disease. Rev. Neurol. 168, 802-805.
Ashburner, J., 2012. SPM: a history. NeuroImage 62, 791-800.

Balbastre, Y., Riviere, D., Souedet, N., Fischer, C., Herard, A.S., Williams, S., Vandenberghe, M.E., Flament, J., Aron-Badin, R., Hantraye, P., Mangin, J.F., Delzescaux, T., 2017. Primatologist: a modular segmentation pipeline for macaque brain morphometry. NeuroImage 162, 306-321.

Barnett, J.H., Robbins, T.W., Leeson, V.C., Sahakian, B.J., Joyce, E.M., Blackwell, A.D., 2010. Assessing cognitive function in clinical trials of schizophrenia. Neurosci. Biobehav. Rev. 34, 1161-1177.

Basile, B.M., Hampton, R.R., 2011. Monkeys recall and reproduce simple shapes from memory. Cur. Biol. 21, 774-778.

Baxa, M., Hruska-Plochan, M., Juhas, S., Vodicka, P., Pavlok, A., Juhasova, J., Miyanohara, A., Nejime, T., Klima, J., Macakova, M., Marsala, S., Weiss, A., Kubickova, S., Musilova, P., Vrtel, R., Sontag, E.M., Thompson, L.M., Schier, J., Hansikova, H., Howland, D.S., Cattaneo, E., DiFiglia, M., Marsala, M., Motlik, J., 2013. A transgenic minipig model of Huntington's disease. J. Huntingt. Dis. 2, 47-68.

Beal, M.F., Kowall, N.W., Ellison, D.W., Mazurek, M.F., Swartz, K.J., Martin, J.B., 1986. Replication of the neurochemical characteristics of Huntington's disease by quinolinic acid. Nature 321, 168-171.

Bedard, C., Wallman, M.J., Pourcher, E., Gould, P.V., Parent, A., Parent, M., 2011. Serotonin and dopamine striatal innervation in Parkinson's disease and Huntington's chorea. Parkinsonism Relat. Disord. 17, 593-598.

Bonanno, G., Fedele, E., Versace, P., Raiteri, M., 1989. Functional damage of dopamine nerve terminals following intrastriatal kainic acid injection. Brain Res. 480, 242-248.

Brouillet, E., Conde, F., Beal, M.F., Hantraye, P., 1999. Replicating Huntington's disease phenotype in experimental animals. Prog. Neurobiol. 59, 427-468.

Brouillet, E., Jacquard, C., Bizat, N., Blum, D., 2005. 3-Nitropropionic acid: a mitochondrial toxin to uncover physiopathological mechanisms underlying striatal degeneration in Huntington's disease. J. Neurochem. 95, 1521-1540.

Brownell, A.L., Hantraye, P., Wullner, U., Hamberg, L., Shoup, T., Elmaleh, D.R., Frim, D.M., Madras, B.K., Brownell, G.L., Rosen, B.R., et al., 1994. PET- and MRI-based assessment of glucose utilization, dopamine receptor binding, and hemodynamic changes after lesions to the caudate-putamen in primates. Exp. Neurol. 125, 41-51.

Burns, L.H., Pakzaban, P., Deacon, T.W., Brownell, A.L., Tatter, S.B., Jenkins, B.G., Isacson, O., 1995. Selective putaminal excitotoxic lesions in non-human primates model the movement disorder of Huntington disease. Neuroscience 64, 1007-1017.

Chan, A.W., Xu, Y., Jiang, J., Rahim, T., Zhao, D., Kocerha, J., Chi, T., Moran, S., Engelhardt, H., Larkin, K., Neumann, A., Cheng, H., Li, C., Nelson, K., Banta, H., Zola, S.M., Villinger, F., Yang, J., Testa, C.M., Mao, H., Zhang, X., Bachevalier, J., 2014. A two years longitudinal study of a transgenic Huntington disease monkey. BMC Neurosci. 15, 36

Chan, A.W., Jiang, J., Chen, Y., Li, C., Prucha, M.S., Hu, Y., Chi, T., Moran, S., Rahim, T., Li, S., Li, X., Zola, S.M., Testa, C.M., Mao, H., Villalba, R., Smith, Y., Zhang, X., Bachevalier, J., 2015. Progressive cognitive deficit, motor impairment and striatal pathology in a transgenic Huntington disease monkey model from infancy to adulthood. PLoS ONE 10, e0122335.

Cicchetti, F., Prensa, L., Wu, Y., Parent, A., 2000. Chemical anatomy of striatal interneurons in normal individuals and in patients with Huntington's disease. Brain research. Brain Res. Rev. 34, 80-101.

Crook, Z.R., Housman, D., 2011. Huntington's disease: can mice lead the way to treat ment? Neuron 69, 423-435.

de Almeida, L.P., Ross, C.A., Zala, D., Aebischer, P., Deglon, N., 2002. Lentiviral-mediated delivery of mutant huntingtin in the striatum of rats induces a selective neuropathology modulated by polyglutamine repeat size, huntingtin expression levels, and protein length. J. Neurosci. 22, 3473-3483.

Dias, R., Robbins, T.W., Roberts, A.C., 1996. Primate analogue of the Wisconsin card sorting test: effects of excitotoxic lesions of the prefrontal cortex in the marmoset. Behav. Neurosci. 110, 872-886.

DiFiglia, M., Sena-Esteves, M., Chase, K., Sapp, E., Pfister, E., Sass, M., Yoder, J., Reeves, P., Pandey, R.K., Rajeev, K.G., Manoharan, M., Sah, D.W., Zamore, P.D., Aronin, N., 2007. Therapeutic silencing of mutant huntingtin with siRNA attenuates striatal and cortical neuropathology and behavioral deficits. Proc. Natl. Acad. Sci. U. S. A. 104, 17204-17209.

Emerich, D.F., Cain, C.K., Greco, C., Saydoff, J.A., Hu, Z.Y., Liu, H., Lindner, M.D., 1997. Cellular delivery of human CNTF prevents motor and cognitive dysfunction in a rodent model of Huntington's disease. Cell Transplant. 6, 249-266.

Emerich, D.F., Thanos, C.G., Goddard, M., Skinner, S.J., Geany, M.S., Bell, W.J., Bintz, B., Schneider, P., Chu, Y., Babu, R.S., Borlongan, C.V., Boekelheide, K., Hall, S., Bryant, B., Kordower, J.H., 2006. Extensive neuroprotection by choroid plexus transplants in excitotoxin lesioned monkeys. Neurobiol. Dis. 23, 471-480.

Ferrante, R.J., Kowall, N.W., 1987. Tyrosine hydroxylase-like immunoreactivity is distributed in the matrix compartment of normal human and Huntington's disease striatum. Brain Res. 416, 141-146.

Ferrante, R.J., Kowall, N.W., Cipolloni, P.B., Storey, E., Beal, M.F., 1993. Excitotoxin lesions in primates as a model for Huntington's disease: histopathologic and neurochemical characterization. Exp. Neurol. 119, 46-71.

Ferry, A.T., Ongur, D., An, X., Price, J.L., 2000. Prefrontal cortical projections to the striatum in macaque monkeys: evidence for an organization related to prefrontal networks. J. Comp. Neurol. 425, 447-470.

Field, A., Miles, J., Field, Z., 1991. Discovering Statistics using R.

Fox, J., Friendly, M., Monette, G., 2018. Heplots: Visualizing Tests in Multivariate Linear Models.

Franich, N.R., Fitzsimons, H.L., Fong, D.M., Klugmann, M., During, M.J., Young, D., 2008. AAV vector-mediated RNAi of mutant huntingtin expression is neuroprotective in a novel genetic rat model of Huntington's disease. Mol. Ther. J. Am. Soc. Gene Therapy 16, 947-956.

Gray, M., Shirasaki, D.I., Cepeda, C., Andre, V.M., Wilburn, B., Lu, X.H., Tao, J., 
Yamazaki, I., Li, S.H., Sun, Y.E., Li, X.J., Levine, M.S., Yang, X.W., 2008. Full-length human mutant huntingtin with a stable polyglutamine repeat can elicit progressive and selective neuropathogenesis in BACHD mice. J. Neurosci. 28, 6182-6195.

Gundersen, H.J., Jensen, E.B., Kieu, K., Nielsen, J., 1999. The efficiency of systematic sampling in stereology-reconsidered. J. Microsc. 193, 199-211.

Hantraye, P., Riche, D., Maziere, M., Isacson, O., 1990. A primate model of Huntington's disease: behavioral and anatomical studies of unilateral excitotoxic lesions of the caudate-putamen in the baboon. Exp. Neurol. 108, 91-104.

Hantraye, P., Leroy-Willig, A., Denys, A., Riche, D., Isacson, O., Maziere, M., Syrota, A., 1992a. Magnetic resonance imaging to monitor pathology of caudate-putamen after excitotoxin-induced neuronal loss in the nonhuman primate brain. Exp. Neurol. 118, 18-23.

Hantraye, P., Loc, H.C., Maziere, B., Khalili-Varasteh, M., Crouzel, C., Fournier, D., Yorke, J.C., Stulzaft, O., Riche, D., Isacson, O., et al., 1992b. 6-[18F]fluoro-L-dopa uptake and $[76 \mathrm{Br}]$ bromolisuride binding in the excitotoxically lesioned caudate-putamen of nonhuman primates studied using positron emission tomography. Exp. Neurol. 115, 218-227.

Hazrati, L.N., Parent, A., 1992. The striatopallidal projection displays a high degree of anatomical specificity in the primate. Brain Res. 592, 213-227.

Hedreen, J.C., DeLong, M.R., 1991. Organization of striatopallidal, striatonigral, and nigrostriatal projections in the macaque. J. Comp. Neurol. 304, 569-595.

Hefti, F., Melamed, E., Wurtman, R.J., 1980. Partial lesions of the dopaminergic nigros triatal system in rat brain: biochemical characterization. Brain Res. 195, 123-137.

Herculano-Houzel, S., 2009. The human brain in numbers: a linearly scaled-up primate brain. Front. Hum. Neurosci. 3, 31.

Hodgson, J.G., Agopyan, N., Gutekunst, C.A., Leavitt, B.R., LePiane, F., Singaraja, R., Smith, D.J., Bissada, N., McCutcheon, K., Nasir, J., Jamot, L., Li, X.J., Stevens, M.E., Rosemond, E., Roder, J.C., Phillips, A.G., Rubin, E.M., Hersch, S.M., Hayden, M.R. 1999. A YAC mouse model for Huntington's disease with full-length mutant huntingtin, cytoplasmic toxicity, and selective striatal neurodegeneration. Neuron 23, 181-192.

Howland, D.S., Munoz-Sanjuan, I., 2014. Mind the gap: models in multiple species needed for therapeutic development in Huntington's disease. Mov. Disord. 29, 1397-1403.

Inase, M., Sakai, S.T., Tanji, J., 1996. Overlapping corticostriatal projections from the supplementary motor area and the primary motor cortex in the macaque monkey: an anterograde double labeling study. J. Comp. Neurol. 373, 283-296.

Isacson, O., Brundin, P., Gage, F.H., Bjorklund, A., 1985. Neural grafting in a rat model of Huntington's disease: progressive neurochemical changes after neostriatal ibotenate lesions and striatal tissue grafting. Neuroscience 16, 799-817.

Isacson, O., Riche, D., Hantraye, P., Sofroniew, M.V., Maziere, M., 1989. A primate model of Huntington's disease: cross-species implantation of striatal precursor cells to the excitotoxically lesioned baboon caudate-putamen. Exp. Brain Res. 75, 213-220.

Isacson, O., Hantraye, P., Maziere, M., Sofroniew, M.V., Riche, D., 1990. Apomorphineinduced dyskinesias after excitotoxic caudate-putamen lesions and the effects of neural transplantation in non-human primates. Prog. Brain Res. 82, 523-533.

Jacobsen, J.C., Bawden, C.S., Rudiger, S.R., McLaughlan, C.J., Reid, S.J., Waldvogel, H.J., MacDonald, M.E., Gusella, J.F., Walker, S.K., Kelly, J.M., Webb, G.C., Faull, R.L., Rees, M.I., Snell, R.G., 2010. An ovine transgenic Huntington's disease model. Hum. Mol. Genet. 19, 1873-1882.

Jay, J.R., Dunnett, S.B., 2007. An operant serial implicit learning task (SILT) in rats: task acquisition, performance and the effects of striatal lesions. J. Neurosci. Methods 163, 235-244.

Joel, D., Weiner, I., 2000. The connections of the dopaminergic system with the striatum in rats and primates: an analysis with respect to the functional and compartmental organization of the striatum. Neuroscience 96, 451-474.

Korecka, J.A., Levy, S., Isacson, O., 2016. In vivo modeling of neuronal function, axonal impairment and connectivity in neurodegenerative and neuropsychiatric disorders using induced pluripotent stem cells. Mol. Cell. Neurosci. 73, 3-12.

Kosior, N., Leavitt, B.R., 2018. Murine models of Huntington's disease for evaluating therapeutics. Methods Mol. Biol. 1780, 179-207.

Kruer, M.C., Boddaert, N., Schneider, S.A., Houlden, H., Bhatia, K.P., Gregory, A., Anderson, J.C., Rooney, W.D., Hogarth, P., Hayflick, S.J., 2012. Neuroimaging features of neurodegeneration with brain iron accumulation. AJNR Am. J. Neuroradiol. 33, 407-414.

Lavisse, S., Inoue, K., Jan, C., Peyronneau, M.A., Petit, F., Goutal, S., Dauguet, J., Guillermier, M., Dolle, F., Rbah-Vidal, L., Van Camp, N., Aron-Badin, R., Remy, P., Hantraye, P., 2015. [18F]DPA-714 PET imaging of translocator protein TSPO (18 $\mathrm{kDa}$ ) in the normal and excitotoxically-lesioned nonhuman primate brain. Eur. J. Nucl. Med. Mol. Imaging 42, 478-494.

Leviel, V., Cheramy, A., Glowinski, J., 1979. Role of the dendritic release of dopamine in the reciprocal control of the two nigro-striatal dopaminergic pathways. Nature 280, 236-239.

Levine, M.S., Klapstein, G.J., Koppel, A., Gruen, E., Cepeda, C., Vargas, M.E., Jokel, E.S., Carpenter, E.M., Zanjani, H., Hurst, R.S., Efstratiadis, A., Zeitlin, S., Chesselet, M.F., 1999. Enhanced sensitivity to N-methyl-D-aspartate receptor activation in transgenic and knockin mouse models of Huntington's disease. J. Neurosci. Res. 58, 515-532.

Lin, C.H., Tallaksen-Greene, S., Chien, W.M., Cearley, J.A., Jackson, W.S., Crouse, A.B., Ren, S., Li, X.J., Albin, R.L., Detloff, P.J., 2001. Neurological abnormalities in a knock-in mouse model of Huntington's disease. Hum. Mol. Genet. 10, 137-144.

Lynd-Balta, E., Haber, S.N., 1994. The organization of midbrain projections to the ventral striatum in the primate. Neuroscience 59, 609-623.

Mangiarini, L., Sathasivam, K., Seller, M., Cozens, B., Harper, A., Hetherington, C., Lawton, M., Trottier, Y., Lehrach, H., Davies, S.W., Bates, G.P., 1996. Exon 1 of the HD gene with an expanded CAG repeat is sufficient to cause a progressive neurological phenotype in transgenic mice. Cell 87, 493-506.

Menalled, L., Brunner, D., 2014. Animal models of Huntington's disease for translation to the clinic: best practices. Mov. Disord. 29, 1375-1390.

Menalled, L.B., Chesselet, M.F., 2002. Mouse models of Huntington's disease. Trends Pharmacol. Sci. 23, 32-39.

Meyer, J.S., Obara, K., Muramatsu, K., 1993. Diaschisis. Neurol. Res. 15, 362-366.

Moore, T.L., Killiany, R.J., Herndon, J.G., Rosene, D.L., Moss, M.B., 2005. A non-human primate test of abstraction and set shifting: an automated adaptation of the Wisconsin card sorting test. J. Neurosci. Methods 146, 165-173.

Moran, S., Chi, T., Prucha, M.S., Ahn, K.S., Connor-Stroud, F., Jean, S., Gould, K., Chan, A.W., 2015. Germline transmission in transgenic Huntington's disease monkeys. Theriogenology 84, 277-285.

Morton, A.J., 2018. Large-brained animal models of Huntington's disease: sheep. Methods Mol. Biol. 1780, 221-239.

Morton, A.J., Howland, D.S., 2013. Large genetic animal models of Huntington's disease. J. Huntingt. Dis. 2, 3-19.

Nash, D.R., Kaplan, S.M., Norman, A.B., Sanberg, P.R., 1991. An evaluation of the possible protective effects of neonatal striatal transplants against kainic acid-induced lesions. J Neur. Transp. Plast 2, 75-79.

Navarro, D.J., 2015. Learning Statistics with R: a Tutorial for Psychology Students and Other Beginners. University of Adelaide.

Nieoullon, A., Cheramy, A., Glowinski, J., 1977. Interdependence of the nigrostriatal dopaminergic systems on the two sides of the brain in the cat. Science 198, 416-418.

Palfi, S., Ferrante, R.J., Brouillet, E., Beal, M.F., Dolan, R., Guyot, M.C., Peschanski, M., Hantraye, P., 1996. Chronic 3-Nitropropionic acid treatment in baboons replicates the cognitive and motor deficits of Huntington's disease. J. Neurosci. 16, 3019.

Palfi, S., Brouillet, E., Jarraya, B., Bloch, J., Jan, C., Shin, M., Conde, F., Li, X.-J., Aebischer, P., Hantraye, P., Deglon, N., 2007. Expression of mutated Huntingtin fragment in the putamen is sufficient to produce abnormal movement in non-human Primates. Mol. Ther. J. Am. Soc. Gene Therapy 15, 1444-1451.

Papoutsi, M., Labuschagne, I., Tabrizi, S.J., Stout, J.C., 2014. The cognitive burden in Huntington's disease: pathology, phenotype, and mechanisms of compensation. Mov. Disord. 29, 673-683.

Pettibone, D.J., Kaufman, N., Scally, M.C., Meyer Jr., E., Ulus, I., Lytle, L.D., 1978. Striatal nondopaminergic neurons: possible involvement in feeding and drinking behavior. Science 200, 1175-1177.

Peyronneau, M.A., Saba, W., Goutal, S., Kuhnast, B., Dolle, F., Bottlaender, M., Valette, H., 2013. [(18)F]Fallypride: metabolism studies and quantification of the radiotracer and its radiometabolites in plasma using a simple and rapid solid-phase extraction method. Nucl. Med. Biol. 40, 887-895.

Pouladi, M.A., Morton, A.J., Hayden, M.R., 2013. Choosing an animal model for the study of Huntington's disease. Nat. Rev. Neurosci. 14, 708-721.

Raper, J., Bosinger, S., Johnson, Z., Tharp, G., Moran, S.P., Chan, A.W.S., 2016. Increased irritability, anxiety, and immune reactivity in transgenic Huntington's disease monkeys. Brain Behav. Immun. 58, 181-190.

Regulier, E., Trottier, Y., Perrin, V., Aebischer, P., Deglon, N., 2003. Early and reversible neuropathology induced by tetracycline-regulated lentiviral overexpression of mutant huntingtin in rat striatum. Hum. Mol. Genet. 12, 2827-2836.

Reilmann, R., Schuldenzucker, V., 2018. Minipigs as a large-brained animal model for Huntington's disease: from behavior and imaging to gene therapy. Methods Mol. Biol. 1780, 241-266.

Roberts, A.C., Robbins, T.W., Everitt, B.J., 1988. The effects of intradimensional and extradimensional shifts on visual discrimination learning in humans and non-human primates. Q. J. Exp. Psychol. B Comp. Physiol. Psychol. 40, 321-341.

Roitberg, B.Z., Emborg, M.E., Sramek, J.G., Palfi, S., Kordower, J.H., 2002. Behaviora and morphological comparison of two nonhuman primate models of Huntington's disease. Neurosurgery 50, 137-145 (discussion 145-136).

Ross, C.A., Tabrizi, S.J., 2011. Huntington's disease: from molecular pathogenesis to clinical treatment. Lancet. Neurol. 10, 83-98.

Sahin, G., Thompson, L.H., Lavisse, S., Ozgur, M., Rbah-Vidal, L., Dolle, F., Hantraye, P., Kirik, D., 2014. Differential dopamine receptor occupancy underlies L-DOPA-induced dyskinesia in a rat model of Parkinson's disease. PLoS ONE 9, e90759.

Schilling, G., Becher, M.W., Sharp, A.H., Jinnah, H.A., Duan, K., Kotzuk, J.A., Slunt, H.H., Ratovitski, T., Cooper, J.K., Jenkins, N.A., Copeland, N.G., Price, D.L., Ross, C.A., Borchelt, D.R., 1999. Intranuclear inclusions and neuritic aggregates in transgenic mice expressing a mutant N-terminal fragment of huntingtin. Hum. Mol. Genet. 8, 397-407.

Schumacher, J.M., Hantraye, P., Brownell, A.L., Riche, D., Madras, B.K., Davenport, P.D., Maziere, M., Elmaleh, D.R., Brownell, G.L., Isacson, O., 1992. A primate model of Huntington's disease: functional neural transplantation and CT-guided stereotactic procedures. Cell Transplant. 1, 313-322.

Schwab, L.C., Garas, S.N., Drouin-Ouellet, J., Mason, S.L., Stott, S.R., Barker, R.A., 2015. Dopamine and Huntington's disease. Expert. Rev. Neurother. 15, 445-458.

Selemon, L.D., Goldman-Rakic, P.S., 1985. Longitudinal topography and interdigitation of corticostriatal projections in the rhesus monkey. J. Neurosci. 5, 776-794.

Senut, M.C., Suhr, S.T., Kaspar, B., Gage, F.H., 2000. Intraneuronal aggregate formation and cell death after viral expression of expanded polyglutamine tracts in the adult rat brain. J. Neurosci. 20, 219-229.

Shear, D.A., Dong, J., Gundy, C.D., Haik-Creguer, K.L., Dunbar, G.L., 1998. Comparison of intrastriatal injections of quinolinic acid and 3-nitropropionic acid for use in animal models of Huntington's disease. Prog. Neuro-Psychopharmacol. Biol. Psychiatry 22, 1217-1240.

Shelbourne, P.F., Killeen, N., Hevner, R.F., Johnston, H.M., Tecott, L., Lewandoski, M., Ennis, M., Ramirez, L., Li, Z., Iannicola, C., Littman, D.R., Myers, R.M., 1999. A Huntington's disease CAG expansion at the murine Hdh locus is unstable and associated with behavioural abnormalities in mice. Hum. Mol. Genet. 8, 763-774.

Takada, M., Tokuno, H., Nambu, A., Inase, M., 1998. Corticostriatal input zones from the supplementary motor area overlap those from the contra- rather than ipsilateral 
primary motor cortex. Brain Res. 791, 335-340.

Thu, D.C., Oorschot, D.E., Tippett, L.J., Nana, A.L., Hogg, V.M., Synek, B.J., Luthi-Carter, R., Waldvogel, H.J., Faull, R.L., 2010. Cell loss in the motor and cingulate cortex correlates with symptomatology in Huntington's disease. Brain J. Neurol. 133, 1094-1110.

Tokuno, H., Inase, M., Nambu, A., Akazawa, T., Miyachi, S., Takada, M., 1999. Corticostriatal projections from distal and proximal forelimb representations of the monkey primary motor cortex. Neurosci. Lett. 269, 33-36.

Tulipan, N., Huang, S., Whetsell, W.O., Allen, G.S., 1986. Neonatal striatal grafts prevent lethal syndrome produced by bilateral intrastriatal injection of kainic acid. Brain Res. 377, 163-167.

Vadori, M., Aron Badin, R., Hantraye, P., Cozzi, E., 2015. Current status of neuronal cell xenotransplantation. Int. J. Surg. 23, 267-272.

von Horsten, S., Schmitt, I., Nguyen, H.P., Holzmann, C., Schmidt, T., Walther, T., Bader, M., Pabst, R., Kobbe, P., Krotova, J., Stiller, D., Kask, A., Vaarmann, A., RathkeHartlieb, S., Schulz, J.B., Grasshoff, U., Bauer, I., Vieira-Saecker, A.M., Paul, M., Jones, L., Lindenberg, K.S., Landwehrmeyer, B., Bauer, A., Li, X.J., Riess, O., 2003. Transgenic rat model of Huntington's disease. Hum. Mol. Genet. 12, 617-624.

Vonsattel, J.P., 2008. Huntington disease models and human neuropathology: similarities and differences. Acta Neuropathol. 115, 55-69.

Vonsattel, J.P., DiFiglia, M., 1998. Huntington disease. J. Neuropathol. Exp. Neurol. 57, 369-384.

Waldvogel, H.J., Kim, E.H., Thu, D.C., Tippett, L.J., Faull, R.L., 2012. New perspectives on the neuropathology in Huntington's disease in the human brain and its relation to symptom variation. J. Huntingt. Dis. 1, 143-153.
Walker, F.O., 2007. Huntington's disease. Lancet 369, 218-228.

Weed, M.R., Taffe, M.A., Polis, I., Roberts, A.C., Robbins, T.W., Koob, G.F., Bloom, F.E., Gold, L.H., 1999. Performance norms for a rhesus monkey neuropsychological testing battery: acquisition and long-term performance. Brain Res. Cogn. Brain Res. 8, 185-201.

West, M.J., Slomianka, L., Gundersen, H.J., 1991. Unbiased stereological estimation of the total number of neurons in thesubdivisions of the rat hippocampus using the optical fractionator. Anat. Rec. 231, 482-497.

Wheeler, V.C., Auerbach, W., White, J.K., Srinidhi, J., Auerbach, A., Ryan, A., Duyao, M.P., Vrbanac, V., Weaver, M., Gusella, J.F., Joyner, A.L., MacDonald, M.E., 1999. Length-dependent gametic CAG repeat instability in the Huntington's disease knockin mouse. Hum. Mol. Genet. 8, 115-122.

Yan, S., Tu, Z., Liu, Z., Fan, N., Yang, H., Yang, S., Yang, W., Zhao, Y., Ouyang, Z., Lai, C., Li, L., Liu, Q., Shi, H., Xu, G., Zhao, H., Wei, H., Pei, Z., Li, S., Lai, L., Li, X.J., 2018. A Huntingtin Knockin pig model recapitulates features of selective Neurodegeneration in Huntington's disease. Cell 173, 989-1002(e1013).

Yang, S.H., Cheng, P.H., Banta, H., Piotrowska-Nitsche, K., Yang, J.J., Cheng, E.C., Snyder, B., Larkin, K., Liu, J., Orkin, J., Fang, Z.H., Smith, Y., Bachevalier, J., Zola, S.M., Li, S.H., Li, X.J., Chan, A.W., 2008. Towards a transgenic model of Huntington's disease in a non-human primate. Nature 453, 921-924.

Yelnik, J., Francois, C., Percheron, G., Tande, D., 1991. Morphological taxonomy of the neurons of the primate striatum. J. Comp. Neurol. 313, 273-294.

Yeterian, E.H., Pandya, D.N., 1991. Prefrontostriatal connections in relation to cortical architectonic organization in rhesus monkeys. J. Comp. Neurol. 312, 43-67. 